\title{
EL FRACASO EN HUNGRÍA DEL FORTALECIMIENTO INSTITUCIONAL CONSTITUCIONAL: LOS ELEMENTOS INSTITUCIONALES INFORMALES COMO PRECONDICIONES Y COMO CONSECUENCIAS DE LA EFICACIA FORMAL DE LAS NORMAS JURÍDICAS
}

\author{
ANDRÁS JAKAB ${ }^{1}$ \\ Catedrático de Derecho Constitucional y Administrativo \\ Universidad de Salzburgo
}

\begin{abstract}
SUMARIO
I. Los elementos institucionales informales: prácticas y narrativas. II. La Constitución húngara de 2010/2011: su proceso de elaboración desde la perspectiva del fortalecimiento institucional. III. Qué hacer: manual del fortalecimiento institucional en el contexto de la Hungría contemporánea.
\end{abstract}

El pensamiento jurídico húngaro padece de una dolencia singular, que, a falta de una mejor denominación, he venido en calificar como obsesión normativa. Esto es, que la gran mayoría de los académicos, los abogados ejercientes y la sociedad en general entienden el Derecho como un mero batiburrillo normativo o eventualmente, en su caso, como un simple sistema de normas. O dicho con otras palabras, se ignoran completamente otros aspectos del funcionamiento del Ordenamiento Jurídico. Y no me refiero con ello necesariamente a la práctica judicial interpretativa (a la jurisprudencia), aunque esta también desconoce en ocasiones dichos aspectos, sino más bien al hecho de este desconocimiento afecta también a los destinatarios reales de las normas, así como a las narrativas en las que aquellas que aquellas se sustentan y, en un sentido amplio, a todo lo que abarca desde la razón de ser y la finalidad de la institución, hasta su simbolismo,

1 Versión al castellano de José Ángel Camisón Yagüe, Profesor Contratado Doctor (acreditado por la ANECA a Profesor Titular) de Derecho constitucional en la Universidad de Alicante. 
el discurso público que las envuelve y las actitudes sociales hacia dicha institución ${ }^{2}$. La obsesión normativa que se somete a crítica en este trabajo no se refiere, sin embargo, al estricto cumplimiento de la Ley (puesto que lo que sucede en este sentido es a menudo todo lo contrario), sino más bien se pretende hacer hincapié en la ceguera consciente respecto de su práctica real y también respecto de las narrativas que afectan al funcionamiento del Ordenamiento Jurídico. Mediante el abandono de la perspectiva de la obsesión normativa, y a través de la toma en consideración de las consecuencias de dicha perspectiva, la situación actual puede abordarse de un modo mucho más claro y evidente (lo que ya constituye por sí mismo todo un logro), y en el medio plazo puede eventualmente promover una firme voluntad de cumplimiento de las normas.

Claro está que los diversos problemas existentes en la actualidad en el sistema jurídico húngaro no están provocados solo por la obsesión normativa. Sino que en realidad son, por un lado, el resultado de una serie de diversos problemas culturales generales (entre los que también figura la obsesión normativa), aunque esto solo una pequeña parte; $y$, por otro lado, también traen causa en ciertas decisiones tanto individuales como colectivas que han sido adoptadas por los políticos —asunto este sobre el volveré más adelante-. En cualquier caso, la ceguera ante esta problemática y el consiguiente desamparo de los juristas, pueden efectivamente explicarse en gran medida en virtud de la obsesión normativa.

Desarrollo el objeto del trabajo en tres partes; en primer lugar, discutiendo la naturaleza institucional de la Ley, centrándome para ello en los elementos informales del fortalecimiento institucional; seguidamente, en segundo lugar, paso a tratar, como ejemplo, los problemas relativos a la elaboración de la Constitución existentes durante los años 2010 y 2011. Finalmente, en tercer lugar, presento una serie de propuestas para salir de esta situación. El análisis del caso húngaro puede ser instructivo para comprender las razones que están detrás del debilitamiento que durante el último par de años están sufriendo las instituciones constitucionales de diversos Estados a lo largo y ancho del globo y, espero, puedan contribuir a encontrar el correcto tratamiento ante estos desafíos ${ }^{3}$.

2 Las narrativas en el sentido en el que aquí se utilizan incluyen las normas no escritas de interpretación, vid., por ejemplo, J. BeLL, 'The Importance of Institutions' in The Method \& Culture Comp. L. (M. AdAMS \& D. Heirbaut eds., 2015) (211).

3 Vid, por ejemplo, entre la creciente literatura sobre estos nuevos desafíos, Constitutional Democracy in Crisis? (M. A. Graber \& S. Levinson \& M. Tushnet eds., 2018); T. Ginsburg \& A. Z. Huq, How to Save a Constitutional Democracy (2018); T. Ginsburg \& A. Z. HuQ \& M. Versteeg, The Coming Demise of Liberal Constitutionalism, 85 U. Chi. L. Rev. 239 (2018); E. LuCE, The Retreat of Western Liberalism (2017); Y. Mounk, The People vs Democracy: Why Our Freedom is in Danger and How to Save It (2018); W. SAdurSKI, How Democracy Dies (in Poland): A Case Study of Anti-Constitutional Populist Backsliding (Sydney Law School Legal Studies Research Paper n. ${ }^{\circ}$ 1, 2018), disponible en https://papers.ssrn.com/sol3/papers.cfm?abstract_id=3103491; Regression of Democracy? (G. ERdmann \& M. KNeuer eds., 2011); O. O VArol, Stealth Authoritarianism, 100 Iowa L. Rev. 1673 (2015); D. LANDAU, Abusive Constitutionalism, 47 U.C. Davis L. Rev. 189 (2013); R. STEFAN FoA \& Y. Mounk, The Danger of Deconsolidation: The Democratic Disconnect, Journal of Democracy, July 2016, p. 5; P. Howe, Eroding Norms and Democratic Deconsolidation, Journal of Democracy, Oct. 2017, p. 15. 


\section{LOS ELEMENTOS INSTITUCIONALES INFORMALES: PRÁCTICAS Y NARRATIVAS}

Existen varias definiciones para el concepto de «institución». De entre ellas la definición que más se adecúa para el propósito de esta investigación es la que describe a las instituciones como la integración o, mejor dicho, como la interacción de los siguientes tres componentes: reglas formales, practicas reales y narrativas ${ }^{4}$. Los dos últimos, las prácticas y las narrativas, se configuran conjuntamente como los «elementos informales», cuando se contraponen con las normas «formales». Por su parte, estos elementos informales pueden operar instituciones (no escritas) que llegan a manifestarse incluso como más poderosas que las instituciones formales, siendo la corrupción institucionalizada un ejemplo típico de ello.

Mientras que los distintos componentes se fortalezcan mutuamente entre sí tendremos instituciones fuertes; sin embargo, en caso de discordancias entre ellos, unos y otros se debilitarán recíprocamente, conduciendo a unas instituciones débiles 5 . Hay que tener en cuenta que los elementos informales cambian más lentamente (fenómeno este al se refiere la doctrina como un ejemplo típico de «path dependence»); por otra parte, los cambios formales relevantes, en relación, por ejemplo, con el cambio de régimen, conllevarán con toda probabilidad un debilitamiento de las instituciones. Este debilitamiento exacerba la incertidumbre y la imprevisibilidad, introduciendo tanto el pensamiento a corto plazo como el incumplimiento de las normas 6 . El fortalecimiento institucional es especialmente difícil en sociedades en las que existe una fuerte división respecto de los valores, ya que las correspondientes narrativas estarán llenas de contradicciones; además, este tipo de sociedades se resistirá en mayor medida a nuevas reglas formales que aquellas otras sociedades en las que el orden de valores sea más homogéneo ${ }^{7}$.

Desde una perspectiva institucionalista, la constitución no es meramente una suma de normas constitucionales, sino que también es una práctica concreta de los órganos constitucionales y de las narrativas que envuelven a la constitución (esta últimas pueden ser, por ejemplo, que el fin de la constitución sea la limitación del poder, o que el propósito de la constitución sea la garantía de

4 V. Lowndes \& M. Roberts, Why Institutions Matter: The New Institutionalism in Political Science 46, 77 (2013): 'power is exercised through regulation, practice and storytelling.' Así, por institución no queremos significar la mera suma de las diferentes normas legales sobre una materia, dado que enfáticamente es mucho más que eso.

5 P. Sztompka, The Sociology of Social Change (1993); Piotr Sztompka, Trust: A Sociological Theory (1999); J. Elster Claus Offe \& U. K. Preuss, Institutional Design in Post-Communist Societies: Rebuilding the Ship at Sea (1998).

6 Para más detalles y ejemplos vid. D. GYốRFFY, Trust and Crisis Management in the European Union: An Institutionalist Account of Success and Failure in Program Countries (2018).

7 E. Osтrom, Understanding Institutional Diversity 27 (2005). 
los derechos fundamentales) $)^{8}$. Es típico que los juristas de todo el mundo se centren principalmente en lo primero, en los elementos formales de las instituciones: las normas; sin embargo, es un rasgo húngaro, o más bien post-socialista, considerar que constituye una máxima ignorar con orgullo los otros elementos (por los motivos que explicaremos detalladamente más adelante en el punto 2.3). Los fracasos del desarrollo institucional que se han experimentado en Hungría durante las tres últimas décadas arrojan luz sobre las desventajas que conlleva este enfoque?. Lo mismo puede decirse de la formación jurídica en Hungría, que se circunscribe a recitar la legislación vigente o a reproducir las construcciones doctrinales legales ${ }^{10}$. Esto mismo sucede también en el ámbito de la legislación, donde las narrativas relativas a «¿cuál es realmente el propósito de las políticas públicas legislativas?» son descuidadas en gran medida, sin que se lleven a cabo estudios ni ex ante ni ex post respecto de las condiciones reales, con lo que la función legislativa se reduce a la adopción formal de un acto ${ }^{11}$.

El fortalecimiento institucional es un proceso más complejo de lo que la mayoría de juristas considera (esto es así en todos los lugares, aunque lo es más en países postsocialistas). Los juristas se concentran normalmente en los elementos formales, por ejemplo, en las normas escritas o, eventualmente, en aplicaciones significativas de dichas normas, lo que, aun siendo esencial, no es suficiente para asegurar el buen funcionamiento de las instituciones jurídicas. El fracaso de numerosas constituciones bien diseñadas puede ser explicado por la ingenuidad de la profesión jurídica ${ }^{12}$. Al mismo tiempo es también verdad que constituciones más

8 Las llamadas teorías institucionales (Savigny, Santi Romano, Hauriou, Schmitt, Weinberger, MacCormick) muestran un dibujo muy diverso, ya que, parcialmente se critican respectivamente entre sí. Estas usan una terminología diferente de la que se usa en este artículo para describir la naturaleza de la Ley. Para más detalles vid. Massimo La Torre, Law as Institution 98-121 (2010). Un principio típico de muchas de estas teorías se encuentra más allá los conceptos de ley positiva, que son incluso «instituciones» metafísicas (por ejemplo, el matrimonio), que se realizan mediante las normas positivas (este principio no tiene por qué tener necesariamente conexión con nuestras aportaciones en el presente trabajo.) Para más detalles y crítica vid. Bernd Rüthers, Institutionelles Rechtsdenken im Wandel der Verfassungsepochen 33-37 (1970). El objeto de este trabajo no es la historia de las teorías legales, sino la actual situación húngara, por lo que analizaremos críticamente estas teorías legales. El concepto de institución que se utiliza en el presente trabajo no provienea de ninguna de estas teorías institucionales legales (y este tampoco es un concepto doctrinal), si no más bien de la ciencia política.

9 Sobre este fenómeno en el derecho parlamentario húgaro vid., por ejemplo, P. SMUK, 'Az Országgyúlés' in A magyar jogrendszer állapota 617(A. JAKAB \& G. GAJDusCHEK eds. 2016): 'In several cases, we cannot blame the respective rules of the Standing Rules, but the [lack of] democratic and constitutional culture of the actors responsible for running the legal institutions.' Para los fallos post-soviéticos vid. D. J Galligan \& M. Kurkchiyan (eds.), Law and Informal Practices: The Post-Communist Experience (2003).

10 A. JAKAB, 'A magyar jogi oktatás megújitásához szükséges lépések: Reformjavaslat összehasonlitó áttekintésre alapozva' 4 MJ 204 (2010) (Hung.).

11 G. GAjDuscheK, 'Elókészitetlenség és utólagos hatásvizsgálat hiánya' in, A magyar jogrendszer állapota, supra nota 10., pp. 796-822.

12 En determinadas situaciones, el fortalecimiento institutcional es una misión imposible, vid. por ejemplo, la constitución transicional de la República de Sudán del Sur (2011), que era un texto bien diseñado 
sencillas pueden tener éxito, si las prácticas sociales y las narrativas reemplazan y corrigen las deficiencias de las normas formales. Hasta hace poco las Constituciones de Estados Unidos ${ }^{13}$ y del Reino Unido $^{14}$ eran buenos ejemplos de sistemas que en los que las reglas formales incompletas se suplen mediante elementos institucionales informales. Dado que estas instituciones jurídicas están integradas por diversos componentes, no resulta infrecuente que se separen de los ideales que en su día tenían los creadores de dichas normas formales; o, dicho en otras palabras, debido a su complejidad, la legislación recurre a menudo al método de ensayo y error. Es por ello que no se puede en la práctica remontarse hasta la voluntad de un único sujeto político constituyente, sino que se deben combinar diversas visiones que, en parte, pueden ser incluso contradictorias ${ }^{15}$. Y aunque esto pueda ser una mala noticia para los «founding fathers» y su correspondiente concepción política de aquel momento político fundacional, estos pueden luego con razón negar su responsabilidad en el caso de que la constitución finalmente fracase.

Las instituciones son sistemas integrados por factores inmateriales creados por la mano del hombre que dan lugar a «comportamientos regulares» ${ }^{16}$. De entre estos factores algunos de ellos, de hecho su mayoría, no están escritos y se presuponen a partir de los relatos provenientes de la práctica real. Por ejemplo, cuando se juega al ajedrez uno no debe golpear al oponente, verter sopa hirviendo sobre sus piezas o escupir sobre el reloj, etc. Tampoco una mera descripción formal de los posibles movimientos de las piezas es suficiente para conocer a fondo el juego, ya que en el mismo hay mucho más involucrado. Debemos seguir una serie de costumbres de civilización que hacen que el juego sea en este sentido posible. Esto implica no solo un conocimiento intelectual sino también moral o, para usar un concepto con menos carga emocional, podríamos hablar de un conocimiento cultural. Las normas formales mal diseñadas pueden dar lugar a

y también trataba de considerar la realidad social local, pero que tristemente debido al ambiente de guerra civil fracasó. Aunque la Constitución contenía una normativa formal elegante, Sudán del Sur es un claro ejemplo de Estado fallido. Vid. para más detalles, Thilo Marauhn \& Hatem Elliesie (eds.), Legal transformation in Northern Africa and South Sudan (2015).

13 La Constitución de Estados Unidos es un texto jurídico bastante imperfecto, lleno de contradicciones y lagunas, vid. para más detalles W. N. Eskridge JR. \& S. LEvinson (eds.), Constitutional Stupidities, Constitutional Tragedies (1998).

14 En el Reino Unido algunos de los componentes informales de sus instituciones constitucionales se denominan «convenciones constitucionales». Para más referencias, vid. András Jakab, European Constitutional Language 78, 147, 200-201 (2016).

15 R. E. Goodin, 'Institutions and Their Design' in, The Theory of Institutional Design 28 (Robert E. Goodin ed., 1996).

16 A. GReIf, Institutions and the Path to the Modern Economy: Lessons from Medieval Trade (2006). Sobre una terminología distinta (institución como combinación de normas formales e informales), aunque en un contexto similar, vid. Douglass C. North, Institutions, Institutional Change and Economic Performance 3 (1990). Es possible introducir un cuarto componente de las instituciones entre las normas formales y la practicas reales: las normas informales no escrita. Esto sería efectivamente más preciso, pero para los puntos que quiero tratar en este artículo no me parece necesario recurrir al mismo, que, además complicaría las explicaciones. Es por ello que, en atención a la simplicidad, este componente conceptual no ha sido utilizado aquí. 
instituciones débiles, pero, y esto es aquí lo más relevante, las carencias culturales de los servidores públicos pueden contribuir tanto como el mal diseño de las normas. Una república sin republicanos o una burocracia sin burócratas (en el sentido weberiano) simplemente no van a estar a la altura.

Los caracteres culturales cambian lentamente y no existen «procedimientos de enmienda» disponibles ${ }^{17}$. Existen, sin embargo, algunos ejemplos exitosos a este respecto que vale la pena señalar: más concretamente, las instituciones son capaces de dar gradualmente forma a la cultura ${ }^{18}$. Quizás el ejemplo más ampliamente conocido en este sentido sea la transformación que tuvo lugar en Alemania tras la II Guerra Mundial, una historia de éxito sustentada sobre la base de los siguientes elementos que se enuncian, sin ánimo de ofrecer un listado exhaustivo. (1) En primer lugar, la doctrina jurídica alemana, que tradicionalmente ha tenido un muy alto nivel, ha contribuido al establecimiento de un ordenamiento jurídico formal bien diseñado. (2) Aunque esto no es un factor decisivo (es posible diseñar un excelente modelo constitucional construido sobre el principio del «Estado del Derecho» allí donde la doctrina jurídica es relativamente débil, como evidencia el caso el de los estados escandinavos), esta matriz intelectual sin duda contribuye a la construcción del «Rechtstaat»; en segundo lugar, en lugar de entregarse a la autocompasión, aunque con un considerable retraso, los alemanes hicieron frente a sus errores y pecados del pasado a partir de la década de los sesenta. (Vergangenbeitsbewältigung). Por supuesto que los populistas y los demagogos están siempre dispuestos a ofrecer narrativas simples, presentando excusas en lugar de la dolorosa verdad. Después de la II Guerra Mundial, sin embargo, tanto la élite de Alemania Occidental como la sociedad en general tomaron partido por la honestidad (algo que tuvo lugar tardíamente, aunque, sin embargo, fue precisamente más fácil por el envejecimiento de la generación precedente). Esta postura moral frente al pasado contribuyó a forjar una narrativa creíble respecto al Ordenamiento Jurídico (particularmente respecto de la Grundgesetz), y también respecto al nuevo régimen construido sobre la dignidad humana, la democracia y el Estado de Derecho ${ }^{19}$. La honestidad y la credibilidad del nuevo orden social y político incrementaron aún más la confianza social, que es esencial para que el modelo tenga éxito, dando lugar a un proceso de autofortalecimiento. Aunque hacer frente al pasado no es en este sentido un requisito indispensable para fortalecimiento institucional, sí que

17 Sobre las dificultades de la situación húngara desde otra perspectiva, vid. I. G. Tóth, 'Turánbánya? Értékválasztások, beidegződések és az illiberalizmusra való fogadókészség Magyarországon' in Hegymenet 37-50 (A. JAKAB \& L. URBÁN eds. 2017).

18 J. G. March \& J. P. Olsen, Rediscovering Institutions: The organizational Basis of Politics 17 (1989). 'Not only are institutions man-made, but also men institution-made', vid. C. OfFe, 'Designing Institutions in East European Transitions' en, Institutions and their designs, 208 (R. E. Goodin ed. 1996).

19 Para el debate sobre el rol de la legitimidad moral en la construcción de un sistema jurídico más eficaz (como se ha visto en el ejemplo del Sistema jurídico húngaro) vid. B. Zsolt, 'Bizalom, legitimitás és jogkövetés' in A magyar jogrendszer állapota, supra nota 11, pp. 837-855. 
contribuye ciertamente a su consecución. (3) La presión externa y, en gran medida, la ocupación militar del país (aunque hemos de admitir que esto por sí solo no hubiera sido suficiente) hicieron imposible cualquier vuelta violenta al autoritarismo. Si bien las antiguas ideas nazis no fueron erradicadas ya que de hecho algunos de los antiguos nazis conservaron sus altos cargos y se prestaron mutuamente colaboración como una red (un ejemplo notorio es el Ministerio de Asuntos Exteriores de Alemania Occidental hasta la década de los setenta o algunas Facultades de Derecho), los nuevos valores políticos devinieron en indiscutibles en el debate público, es decir, que no se produjo ninguna contranarrativa pública que rechazara el Estado de Derecho y la democracia. Los alemanes tenían miedo de sí mismos, de su lado oscuro, y conscientemente asumieron sus obligaciones internacionales (mientras que también trataban de pacificar a otras naciones occidentales con su buena disposición a cumplir con dichas obligaciones). La integración europea, incluido el establecimiento del Tribunal Europeo de Derechos Humanos, pueden explicarse en parte debido a esta forma consciente de abordar la situación por parte de Alemania. Siguiendo el ejemplo de Ulises, quién se ató al mástil por temor a ceder a la tentación de las sirenas, los alemanes se pusieron a trabajar con gran fervor en la construcción de instituciones europeas supranacionales. (4) El éxito económico fue, en efecto, el resultado que contribuyó en gran medida a la legitimación de estos valores así como a su internacionalización por la sociedad (el éxito económico, por supuesto, que no guardaba relación con las instituciones democráticas sometidas al Estado de Derecho, consagradas en la Constitución). Daron Acemogluy ha escrito ampliamente sobre esta cuestión en su bestseller Why Nations Fail ${ }^{20}$. (5) Existía un consenso entre la élite alemana para adherirse a la democracia y al Estado de Derecho. De hecho, sin el consentimiento por el que las élites se limitan a sí mismas, las democracias liberales serían disfuncionales ${ }^{21}$. Este consenso se vio respaldado por la extinción física de las antiguas elites enfrentadas (incluida la exclusión parcial de los nazis de la vida pública), la presión de América, el miedo a la Unión Soviética y por haber saboreado el éxito económico.

Cuando vemos ejemplos exitosos de fortalecimiento institucional constitucional, resulta claro que ciertas formas de presión internacional juegan un papel

20 D. Acemoglu \& J. A. Robinson, Why Nations Fail: The Origins of Power, Prosperity and Poverty (2012). Para un análisis metodológicamente más complicado con unos resultados similares vid. R. RigOBON \& D. Rodrik, 'Rule of Law, Democracy, Openness and Income: Estimating Interrelationships' 2 NBER Working Paper Series (2004) www.nber.org/papers/w10750.pdf: ' $[D$ femocracy and the rule of law are both good for economic performance, but the latter has a much stronger impact on incomes. Openness (trade/GDP) has a negative impact on income levels and democracy, but a positive effect on rule of law. Higher income produces greater openness and better institutions, but these effects are not very strong. Rule of law and democracy tend to be mutually reinforcing.' Sobre el efecto de las democracias liberales y su contribución al crecimiento económico vid. M. YANOvSKIY \& T. Ginker, 'A proposal for a more objective measure of de facto constitutional constraints' 28 Const. Pol. Econ. 311 (2017).

21 J. Higley \& M. Burton, Elite Foundations of Liberal Democracy (2006). 
importante por lo a que su éxito se refiere ${ }^{22}$. En algunos casos, como en Austria o Japón, adoptó la forma de una intervención militar directa, en otros casos, el miedo a una posible ocupación extranjera cambió la forma de ver las cosas en las élites locales (conduciéndolas hacia el consenso), como el caso de Estonia, que tenía un temor bien fundado respecto de Rusia, debido al éxito de su andadura que comenzó en los años noventa ${ }^{23}$.

Se puede así considerar que las prácticas y narrativas corruptas y autoritarias son similares al alcoholismo: en teoría es posible para el paciente currarse por sí mismo, sin embargo, normalmente, una recuperación completa precisa no solo de la voluntad de mejorar sino también de ayuda externa ${ }^{24}$. Es más, una vez que el paciente parece haberse recuperado, este necesita aún de supervisión para no recaer. Esto es exactamente lo mismo que está ocurriendo en algunos de los antiguos estados socialistas quienes, después de haber entrado en la Unión Europea, ya no están sometidos a la estricta y continua supervisión que experimentaron antes su adhesión (condiciones durante la fase de preadhesión), con el resultado de que han dejado de sentir la necesidad de respetar las normas de civilización de las democracias liberales occidentales ${ }^{25}$.

Un proceso de aprendizaje exitoso requiere de un periodo de tiempo considerable, un control constante de las capacidades necesarias y del refuerzo positivo (referido a las experiencias de los logros morales y económicos alcanzados); en el caso de Hungría, y también en el de otros antiguos estados socialistas, dichos requisitos (o, eventualmente, alguno de ellos) no se han dado. Por expresarlo de otro modo: el andamiaje se desmanteló demasiado pronto y las instituciones del Estado de Derecho, que estaban solo preparadas a medias, colapsaron parcialmente en varios de los estados postsocialistas. Esto puede verse claramente en varios de los índices que sirven para supervisar el Estado de Derecho (Bertelsmann, World Justice Project y Freedom House), que indican una lenta erosión en los países socialistas desde que tiene lugar su adhesión a la Unión Europea. Esto es bastante evidente en los casos de Hungría, Croacia y Polonia, aunque

22 M. J. Gorges, 'New Institutionalist Explanations for Institutional Change: A Note of Caution' 21 Pol. 137 (2001).

23 Esto, sin embargo, tiene el efecto negativo de excluir a la población rusa local de la democracia de Estonia. Vid, con referencias al fondo étnico de la élite comunista antes de 1990. D. Bohle \& B. GreskoviTs, Capitalist Diversity on Europe's Periphery 99 (2012). El relativo buen desarrollo de los estados bálticos (si se compara con otros estados post-soviéticos) puede ser explicado en parte por el consenso entre la élite local, vid. M. MeNDELSKI, 'The EU's rule of law promotion in post-Soviet Europe: what explains the divergence between Baltic States and EaP countries?’ 7 E.J. Eur.Stud. 111 (2016).

24 Sobre la necesidad de presión internacional para lograr acabar satisfactoriamente con la corrupción, vid. por ejemplo, A. Mungiu-PipPidi, 'Corruption: Diagnosis and Treatment' 17 J. Democracy. 86 (2006). Sobre la metáfora del alcoholismo en un contexto concreto (alcoholismo fiscal) vid. G. Kopits, 'Saving Hungary's Finances: Budapest's four step-plan for fiscal alcoholics' Wall St. J. Eur., Dec. 4, 2008.

25 Sobre las deficiencias del mecanismo de refuerzo de la UE vid. A. JAKAB \& D. Kochenov (eds.), The Enforcement of EU Law and Values (2017); L. PECH \& K. LANE SCHEPPELE, 'Illiberalism Within: Rule of Law Backsliding in the EU' 19 Cambridge Yearbook of European Legal Studies 3 (2017). 
también puede entreverse en otros Estados ${ }^{26}$. El modelo jurídico occidental solo puede funcionar bien en el largo plazo si aquellos que operan el sistema también internalizan los propios valores occidentales. Estas condiciones culturales pueden ser establecidas, pero cautelosamente y muy despacio, de modo que, ciertamente, la mera adopción de nuevas leyes no será suficiente por sí misma. Cuando la internalización de estos valores no tiene lugar y la ciudadanía no se siente comprometida con ellos, lo que significa que consideran que no tienen nada que ganar; entonces tan pronto como decae la presión internacional, los reflejos paganos (las formas anteriores a la democracia y al Estado de Derecho) resurgen y la máscara cae: primero en el nivel (retórico) de las narrativas y las prácticas, para seguidamente continuar pronto con la destrucción de las instituciones formales ${ }^{27}$.

Rumanía es posiblemente un contraejemplo a este respecto; en este caso las instituciones y ciertos aspectos del Estado de Derecho se han fortalecido tras la adhesión a la Unión Europea (aunque este fortalecimiento sea mínimo es relativamente significativo, tomando en consideración el declive general de la región). Sin embargo, esta mejora no se debe a una repentina iluminación de la élite rumana o su menor propensión a la corrupción, sino más bien a la cláusula de salvaguardia que el Tratado de adhesión de Rumanía contiene en referencia a un periodo posterior a su entrada en la $\mathrm{UE}^{28}$. Concretamente, se introduce el llamado «mecanismo de cooperación y verificación», que básicamente significa que Rumania se somete anualmente a evaluación sobre la base de una serie de criterios predefinidos y en caso de que las medidas necesarias que la propia Rumanía adopte contra la corrupción fracasen, será la Comisión Europea la que adopte «las medidas apropiadas». Aunque no se ha determinado el contenido específico de estas medidas (por ejemplo, la cancelación de ciertos pagos) y aunque en la práctica tales medidas nunca han llegado a aplicarse, lo que hace en realidad que este mecanismo sea tan efectivo no es la posibilidad de establecer sanciones formales, sino la vinculación informal de los resultados reflejados en los informes anuales por parte de ciertos estados occidentales para permitir el acceso de Rumania a la zona Schengen y también el prestigio de la Unión Europea - y en consecuencia de dichos informes anuales_- a los ojos de la sociedad rumana ${ }^{29}$. Los informes

26 Con unas consideraciones similares vid. J. DAwSON - S. HANLEY, 'What's Wrong with East-Central Europe? The Fading Mirage of the "Liberal Consensus»' 27 J. Dem. 20 (2016). Sobre la erosión del constitucionalismo esloveno (explicada sobre las deficiencias culturales y esperando ayuda externa, especialmente de la UE), vid. Matej Avbelj, 'The Sociology of (Slovenian) Constitutional Democracy' 1 HAGUE J. RULE L. (2017). Para una visión general vid. M. BRusis, Illiberale Drift und Proliferation - BTI-Regionalbericht Ostmittel- und Südosteuropa (2018).

27 T. SNyder, On Tyranny: Twenty Lessons from the Twentieth Century 32 (2017), 'The symbols of today enable the reality of tomorrow.

28 R. CARP, 'The Struggle for the Rule of Law in Romania as an EU Member State: The Role of the Cooperation and Verification Mechanism' 10 Utrecht L. Rev. (2014), www.ssrn.com/abstract $=2395170$.

29 Este mecanismo también se aplica a Bulgaria (según lo establecido en su Tratado de Adhesión) pero debido al desafortunado desarrollo en Bulgaria de su política doméstica, ha resultado menos efectivo. No existe garantía de que la mejora rumana continúe, los intentos para establecer medidas anticorrupción 
anuales son un punto de referencia para el discurso público en Rumanía; tanto sus recomendaciones como su contenido tienen un peso específico importante. Por ejemplo, cuando la élite rumana intentó relajar las normas anticorrupción en febrero de 2017, se desataron manifestaciones multitudinarias. Pero más importante que el abandono del cambio normativo propuesto fue la condena al respecto que planteó la Comisión Europea, que expresamente se remitió al mecanismo de cooperación y verificación (si bien esto fue menos espectacular y recibió una menor cobertura por parte de los medios de comunicación) $)^{30}$.

\section{LA CONSTITUCIÓN HÚNGARA DE 2010/2011: SU PROCESO DE ELABORACIÓN DE DESDE LA PERSPECTIVA DEL FORTALECIMIENTO INSTITUCIONAL}

A la luz de lo indicado anteriormente, es preciso tener en cuenta cómo se pueden evaluar desde el punto de vista del fortalecimiento institucional los cambios constitucionales de los últimos años en Hungría. ¿Hasta qué punto los elementos institucionales se han reforzado mutuamente? Es decir, ¿las reglas formales, las prácticas reales y las narrativas han dado como resultado instituciones estables (resistentes y duraderas) y fuertes (capaces de determinar el comportamiento humano) o, por el contrario, se debilitan entre sí a causa de su carácter irreconciliable? ¿Las nuevas características institucionales mejoran la previsibilidad, promoviendo un pensamiento a largo plazo y la observancia de la Ley? Y en caso de que sí lo hicieran, ¿esto conlleva a la prosperidad de la nación en su dimensión social? A continuación trataré en detalle esta cuestión; pero de antemano el resumen de la respuestas que ofreceré es que lamentablemente no es así. Desafortunadamente, la elaboración de la constitución de 2012/2011 puede considerarse un fracaso por dos razones: en primer lugar, debido a la falta de coherencia entre cada uno de los elementos (reglas, prácticas y narrativas), esto hace que las instituciones sean menos estables y, por tanto, cada vez más incapaces de promover el cumplimiento de la Ley; en segundo lugar, las instituciones que se establecieron finalmente son menos adecuadas para contribuir a la prosperidad de la comunidad política.

continúan; el éxito es en este caso el resultado de una constelación afortunada en la política doméstica, (equilibrio de poderes, relaciones personales, protestas masivas, y presión externa de la Unión Europea, para más detalles vid. Ingi Iusmen, 'EU Leverage and Democratic Backsliding in Central and Eastern Europe: the Case of Romania' 53 J. Common Mkt. Stud. 593 (2015); U. Sedelmeier, 'Anchoring Democracy from Above? The European Union and Democratic Backsliding in Hungary and Romania after Accession' $52 \mathrm{~J}$. Common Mkt. Stud. 105 (2014); U. Sedelmeier \& C. LaCatus, 'Compliance with the European Union's Anti-Corruption Conditions in the 'Cooperation and Verification Mechanism': Why is Romania Better than Bulgaria?' 28 MAXCAP Working Papers (2016).

30 J.C. Juncker, Pres. Eur. Comm`n. \& Frans Timmermans First Vice-Pres., Joint Statement on the fight against corruption in Romania, (Feb. 1, 2017), www.europa.eu/rapid/press-release_STATEMENT17-195_en.htm. 


\section{El texto formal: pocos cambios - mejora parcial, empeoramiento parcial}

Comparados con la gran cantidad de cambios institucionales, los cambios realizados en las reglas formales son relativamente menores, la nueva Ley Fundamental básicamente mantiene el sistema normativo y el texto de la anterior Constitución ${ }^{31}$, con algunas mejoras en la codificación, e incluyendo también ciertos cambios sustanciales positivos como la previsión sobre limitación de la deuda. Quizás quienes llevaron a cabo la reforma se dieron cuenta de que podría haber resultado muy arriesgado comenzar a experimentar, por lo que desecharon diversas propuestas normativas como introducir un sistema semipresidencialista o un modelo parlamentario bicameral (Hungría mantiene su sistema parlamentario unicameral).

Más allá de las normas que únicamente tienen una mera relevancia simbólica, el texto estaba salpicado de excepciones ad hoc, mediante las cuales los redactores llevaron a acabo ciertos ajustes, tanto sobre las normas relativas a la organización del Estado como sobre los derechos fundamentales, con el objeto de que estas normas estuvieran orientadas en el sentido de los intereses reales o percibidos por el partido (en especial esto puede verse en las disposiciones referidas a los tribunales ordinarios, el Tribunal Constitucional o las confesiones religiosas). En ocasiones el resultado querido no fue alcanzado a la primera, por lo que las excepciones tuvieron que ser enmendadas y re-enmendadas. Estas vergonzosas repeticiones trajeron causa del hecho de que la mayoría de los expertos en Derecho constitucional dejaron, uno tras de otro, de tomar parte en el proceso de elaboración y toma de decisiones. Ello se debió a que, por un lado, sus opiniones no se tenían realmente en cuenta y, por otro lado, tuvieron que hacer frente a una situación en la que su ética profesional respecto de necesaria limitación del poder estatal estaba en conflicto con la línea que se les pidió que adoptaran.

En este contexto, todos los controles establecidos sobre aquellos que tenían que tomar las decisiones quedaron fundidos, y únicamente la presión ejercida por las Instituciones de la Unión Europea y por otros actores internacionales (principalmente los Estados Unidos y los mercados financieros internacionales) actuaron

31 De una parte, esto es favorable, como las tradiciones liberal democráticas (esp. case-law) han tenido una alta probabilidad de sobrevivir. De otra parte, sin embargo, esto es desfavorable porque lo observadores superficiales (por, ejemplo, aquellos que solo tienen en cuenta las normas legales, pero no la prácticas y narrativas reales), pueden tener la falsa impresión de que los cambios han sido menores. Para más detalles, vid. A. Jakab, P. Sonnevend \& L. Csink, 'The Constitution as an Instrument of Everyday Party Politics: The Basic Law of Hungary' in, Constitutional Crisis in the European Constitutional Area 33 (A. Von Bogdandy \& P. SonNEvend eds. 2015); A. Vincze \& M. Varju, 'Hungary: The New Fundamental Law' 18 Eur. Pub. L. 437 (2012); K. Lane Scheppele, Autocratic Legalism, 85 U. Chi. L. Rev. 545 (2018); K. Lane Scheppele, The Rule of Law and the Frankenstate: Why Governance Checklists Do Not Work, 26 Governance 559 (2013); M. Bánkúti, G. Halmai \& K. Lane Scheppele, Hungary's Illiberal Turn: Disabling the Constitution, 23 Journal of Democracy, July 2012, p. 138; M. BogAARDS, De-democratization in Hungary: diffusely defective democracy, 25 Democratization 1 (2018); I. Pogany, The Crisis of Democracy in East Central Europe: The 'New Constitutionalism' in Hungary, 24 European Public Law 341, 352 (2013). 
como el único límite al ejercicio de la mayoría reforzada con capacidad de cambiar la Constitución que existió hasta 2015 (y que los partidos de gobierno recuperaron en 2018 al alcanzar la mayoría de dos tercios, necesaria para aprobar el cambio en la Constitución) $)^{32}$.

Esta tendencia ya era visible en el momento del proceso de los años 2010/2011, y se hizo especialmente patente con la Quinta Reforma de la Ley Fundamental, que vino impuesta al Gobierno por Bruselas, Venecia, Estrasburgo y Luxemburgo, con la que se buscaba remediar las deficiencias constitucionales más graves que afectaban a la normativa europea. De hecho, esta circunstancia se reconocía incluso en la exposición de motivos que se adjuntaba a la Reformas donde se indicaba: «Por lo tanto, al objeto de prevenir que ciertas previsiones constitucionales puedan servir como pretexto para atacar a Hungría, el Gobierno, sin abandonar su intención original (...), propone una solución diferente.»

\section{La práctica real: la erosión gradual del Estado de Derecho}

Después del 2010, el funcionamiento real del Ordenamiento Jurídico estuvo marcado tanto por un incremento en la instrumentalización de la legislación, esto es, en el uso de la facultad legislativa como una herramienta de poder político; como por un aumento de la incertidumbre, que socavaba la seguridad jurídica ${ }^{33}$. (Desde la perspectiva constitucional, el modo en el que se elaboran las leyes es parte de la práctica real). A partir de entonces, el número de leyes promulgadas ha ido creciendo de forma continuada, con plazos cada vez menores por lo que a su adopción de refiere, lo que desde el punto de vista de la certeza del Derecho es un elemento desfavorable ${ }^{34}$, y tiene, además, un impacto negativo sobre la calidad de la legislación, que requiere de frecuentes modificaciones, lo que provoca efectos especialmente adversos en la seguridad jurídica ${ }^{35}$.

32 Las elecciones de 2018 han sido duramente criticadas por la OSCE, vid. Statement, OSCE/ODIHR, Limited Election Observation Mission, (Apr. 8, 2018), www.osce.org/odihr/elections/hungary/377410?download =true: 'The 8 April parliamentary elections were characterised by a pervasive overlap between state and ruling party resources, undermining contestants' ability to compete on an equal basis. Voters had a wide range of political options but intimidating and xenophobic rhetoric, media bias and opaque campaign financing constricted the space for genuine political debate, hindering voters' ability to make a fully-informed choice.'

33 Sobre la falta de certeza jurídica vid. JAKAB \& GAJDUSCHEK, A magyar jogrendszer állapota, supra nota 10. Péter Tölgyessy, 'Politika mindenekelótt: Jog és hatalom Magyarországon' p.17; A. SZALAI \& A. JAKAB, 'Jog mint a gazdasági fejlödés infrastruktúrája',p. 116; G. GAJDusCHEK, 'Elókészítetlenség és utólagos hatásvizsgálat biánya' p. 796; C. I. NAGY, 'Esettanulmány a jogbiztonsággal kapcsolatos problémákról: a választottbíráskodásra vonatkozó szabályozás változásai', p. 856.

34 Esto no es una tendencia general en el mundo vid. por ejemplo, The British data Michael Zander, The Law-Making Process 1 (2004).

35 Para las estadísticas de modificación de leyes recientemente adoptadas, vid. M. SEBÖK, B. KUBIK \& C. Molnár, 'A törvények formális minösége — egy empirikus vázlat' in, Trendek a magyar politikában 2. A Fidesz és a többiek: pártok, mozgalmak, 300, 304 (Zsolt Boda \& Andrea Szabó eds.2017). 
La práctica real, particularmente dentro del ámbito del Derecho constitucional, se desvía cada vez más de los que se prevé en las reglas formales. Estas prácticas, sin embargo, son difíciles de precisar mediante métodos jurídicos tradicionales $^{36}$. Las infracciones que se manifiestan en la práctica real son destructivas cuando bien alcanzan un nivel crítico, cuando estas solo puedan explicarse en referencia a una excepción implícita, o cuando la regla se cuestione en el nivel de la narrativa. Aunque puedan cometerse anualmente varios homicidios en Hungría, allí no se cuestiona la fortaleza de la protección de la vida como institución ${ }^{37}$. Sin embargo, si el pueblo húngaro fuera testigo de un gran número de homicidios, como sucede en Méjico o en Filipinas con el apoyo de la narrativa oficial del Gobierno, o si asistiera al asesinato rutinario de periodistas de la oposición (como es el caso de Rusia donde se han producido extraños homicidios que nunca han sido investigados), ello indicaría un debilitamiento de la institución.

Desgraciadamente, en Hungría se ha asistido a varios casos de debilitamiento de instituciones constitucionales. La siguiente es una lista que, sin ser exhaustiva, presenta una serie de ejemplos: (1) En primer lugar, aunque el Tribunal Constitucional muestra eventualmente algún signo vital cuando adopta ciertas decisiones sobre asuntos de menor entidad, resulta evidente para los juristas, y ahora también para los legos, que el Tribunal simplemente teme resolver o, en su caso, no quiere adoptar ciertos pronunciamientos que, necesariamente, deberían seguir lo indicado en la Ley Fundamental. Un ejemplo reciente y realista de lo indicado sería la aplicación de la lógica jurídica en sentido estricto respecto de la manifiesta inconstitucionalidad de la lex $\mathrm{CEU}^{38}$, sin que pueda ser tenida por una táctica dilatoria como, por ejemplo, sí lo sería la designación de un comité de expertos que hubiera preparar un extenso informe preliminar. Aunque desde un punto de vista jurídico, no cabe objeción, sin embargo, en el nivel de la práctica real esto equivale a la destrucción institucional; minando la confianza en la independencia del Tribunal Constitucional y con razón, y desacreditando gradualmente la narrativa de la separación de poderes ${ }^{39}$. (2) En segundo lugar, existe un significativo número de casos, algunos de ellos denunciados por los medios de

36 La discrepancia está programada en la naturaleza del régimen; si las normas formales (y, en ciertos casos, también la retórica política) más o menos conformes con las ideas del constitucionalismo, entonces esto puede conferir legitimidad al régimen, de modo que su desaparición total parace improbable, considerando que cada vez nos encontramos más excepciones en las prácticas reales. La tensión entre los elementos formales e informales no ese este sentido un defecto, sino que desde la perspectiva de la práctica política es algo bastante lógico en este régimen.

37 OFFE, supra nota 8, p. 206.

38 Para un análisis empírico de la influencia del gobierno sobre el Tribunal Constitucional vid. Z. Szente, 'The Political Orientation of the Members of the Hungarian Constitutional Court between 2010 and 2014' Const. Stud.1.1 123 (2016).

39 Sobre el último movimiento del Tribunal Constitucional, que en esta acasión constituye una clara quiebra de sus normas procesales. vid. G. Halmai, 'The Hungarian Constitutional Court betrays Academic Freedom and Freedom of Association' Verfassungsblog (June 8., 2018), www.verfassungsblog.de/the-hungarianconstitutional-court-betrays-academic-freedom-and-freedom-of-association/. 
comunicación, que ponen en cuestión la aplicación de diversas prácticas materiales por lo que a la selección de la presidencia de los tribunales de justicia (que, no olvidemos, siguen jugando un significativo papel respecto del reparto de asuntos dentro de cada uno de sus respectivos órganos judiciales), en tanto que la relación personal con el Presidente de la Oficina Nacional del Poder Judicial tiene más peso en la decisión que el criterio oficial de mérito y capacidad. Esta práctica, que en la mayoría de los casos no supone una quiebra relevante de las reglas del procedimiento de selección, aunque alguna vez excepcionalmente esto sí ocurre, se produce desde que gran parte de dichas reglas se elaboraran por parte del propia Oficina Nacional del Poder Judicial, algo que infringe los principios generales que deben conducir estos procesos al no tenerlos en cuenta. Todo ello corroe dolorosamente los elementos informales sobre los que se constituye la independencia judicial $^{40}$. (3) En tercer lugar, si bien la Ley Fundamental respalda la idea de autogobierno, en realidad se basa en la centralización completa y general del Estado, en parte a través de las leyes formales de implementación y de la re-regulación de competencias y, en parte, mediante la realización práctica de la financiación, donde la distribución de los fondos se lleva a cabo de forma discrecional y poco transparente ${ }^{41}$. Si bien las normas formales de lucha contra la corrupción se mantienen, los servicios anticorrupción siguen funcionando sin transparencia ni garantías. Entre tanto, se ha publicado una sucesión de informes periodísticos, que no han sido refutados, en los que se señala que la Oficina del Fiscal General, cuando se trata de formular cargos respecto de sospechas relativas presuntos delitos cometidos por personas cercanas al Gobierno, no ha adoptado ninguna medida o a demorado su actuación o, incluso, se ha conducido con una espectacular torpeza. Incluso la corrupción, en un sentido amplio, aparece eventualmente en el nivel legislativo, como ocurre en la normativa sobre apuestas o sobre venta minorista de tabacos ${ }^{42}$. Aunque la normativa formal establece que uno de los objetivos de la Autoridad Nacional de Medios de Infocomunicaciones y del Consejo de Medios de Comunicación es promover el pluralismo de los medios de comunicación, en el marco de la práctica real, ambos están trabajando visiblemente de forma que todo el panorama de los medios se conduzca hacia las posiciones el gobierno, en parte mediante una aplicación incompleta de las normas y, en parte,

40 M. BENCZE \& A. BADó, 'A magyar birósági rendszer hatékonyságát és az itélkezés színvonalát befolyásoló strukturális és személyi feltételek' in, A magyar jogrendszer állapota, supra nota 11, p. 441, 'A bírói önigazgatás kiüresedése, a politikai befolyás lehetősége, konformitási kényszer megjelenése.'

41 I. P. KovÁcs, 'Modellváltás a magyar önkormányzati rendszerben' in, A magyar jogrendszer állapota, supra nota 10 , pp. 583-599.

42 Con documentación detallada, vid. M. Ligeti, 'Korrupció' in, A magyar jogrendszer állapota, supra nota 11, pp. 727-757. Además, como narrativa, la evidente corrupción sistematizada es abiertamente defendida por algunos intelectuales próximos al gobierno en medios de comunicación amigos que se han conformado como una nueva clase capitalista. Vid. la infame entrevista con András Lánczi, Prof., Corvinus Universtity Budapest, in Magyar Idők (Dec. 21 2015), www.magyaridok.hu/belfold/lanczi-andras-viccpartokszinvonalan-all-az-ellenzek-243952/. 
por manifiestas violaciones del ordenamiento, tal y como ha sido sentenciado por los Tribunales ${ }^{43}$. (6) En sexto lugar, la protección de la propiedad privada continúa formando formalmente parte del Ordenamiento Jurídico de Hungría, si bien se ha deteriorado seriamente o, al menos, se ha tornado singular en varios puntos. Así, más allá del hecho que desde 2010 hasta el día de hoy las competencias del Tribunal Constitucional permanecen incompletas —en tanto que el Tribunal no puede revisar en relación con el derecho de propiedad las leyes de naturaleza fiscal o presupuestaria-, es posible encontrar repetidos casos en los que una empresa es, primeramente, despojada por el Estado de su participación en el mercado mediante la introducción de enmiendas legislativas —que por sí mismas no pueden ser objetadas formalmente)_; dicha participación posteriormente se transmite por la vía de los hechos a personas jurídico privadas (como, por ejemplo, sucede con las leyes sobre apuestas); $y$, finalmente, se introducen estrictas reglas formales como el paso siguiente para proteger al nuevo titular de esa participación. De hecho, es el propio concepto de propiedad privada lo que se vuelve relativo cuando se trata de obtener una imagen clara de la verdadera situación financiera de los principales políticos. Y esto sucede no solo por las distintas opciones contractuales sino también por la vinculación de los políticos a específicas formas de propiedad privada, en las que quien esté registrado como propietario es una mera formalidad ${ }^{44}$. Gracias a la tragicómica forma en la que se manejas las declaraciones patrimoniales de los políticos tampoco se tiene una idea clara de la riqueza de los políticos, incluso cuando los activos están a inscritos a su nombre (si bien no hay nada nuevo en referencia en relación con este asunto, el grado y notoriedad de las discrepancias existentes entre la realidad y las declaraciones van más allá lo que había sucedido anteriormente).

Aquellos a los que corresponde adoptar las decisiones carecen por completo del sentido de responsabilidad para resistir tales tenciones, aunque esto vaya en contra de su interés a largo plazo, y de que, tal y como se indica, están desmantelando activamente la constitucionalidad, por ejemplo, del sistema de normas jurídica que limita el gobierno, mientras que al mismo tiempo respaldan formalmente las normas constitucionales, que finalmente quedan en simple palabrería ${ }^{45}$.

Sin descender a las extensas construcciones académicas, estas situaciones pueden describir de forma exhaustiva, aunque breve, mediante los conocidos

43 G. Polyák \& K. Nagy, 'A médiatörvények kontextusa, rendelkezései és gyakorlata' 20 Jura 127 (2014), www.mediakutato.hu/cikk/2016_03_osz_tel/10_frekvenciaosztogatas.

44 Sobre las entrevistas y los casos estudiados en esta material vid. Dorottya Sallai (Egerszegi) \& Gerhard Schnyder, 'The Transformation of Post-Socialist Capitalism — from Developmental State to Clan State?' (Jan.12, 2018), www.papers.ssrn.com/sol3/papers.cfm?abstract_id=3100775.

45 Sobre este tipo de regimens constitucionales híbridos vid. para más referencias, por ejemplo, R. N. Ortega, Conceptualizing Authoritarian Constitutionalism' 49 Verfassung und Recht in Übersee 339 (2016); S. LEVITSKY \& L. A. WAy, Competitive Authoritarianism: Hybrid Regimes after the Cold War (2010); A. BOZÓKI \& D. Hegedüs, 'An externally constrained hybrid regime: Hungary in the European Union' 25 Democratization 1 (2018). 


\section{Gráfico n. ${ }^{\circ}$ 1. Índice Bertelsmann de Transformación representado en un gráfico con los datos referidos a Hungría durante el periodo 2006-2018}

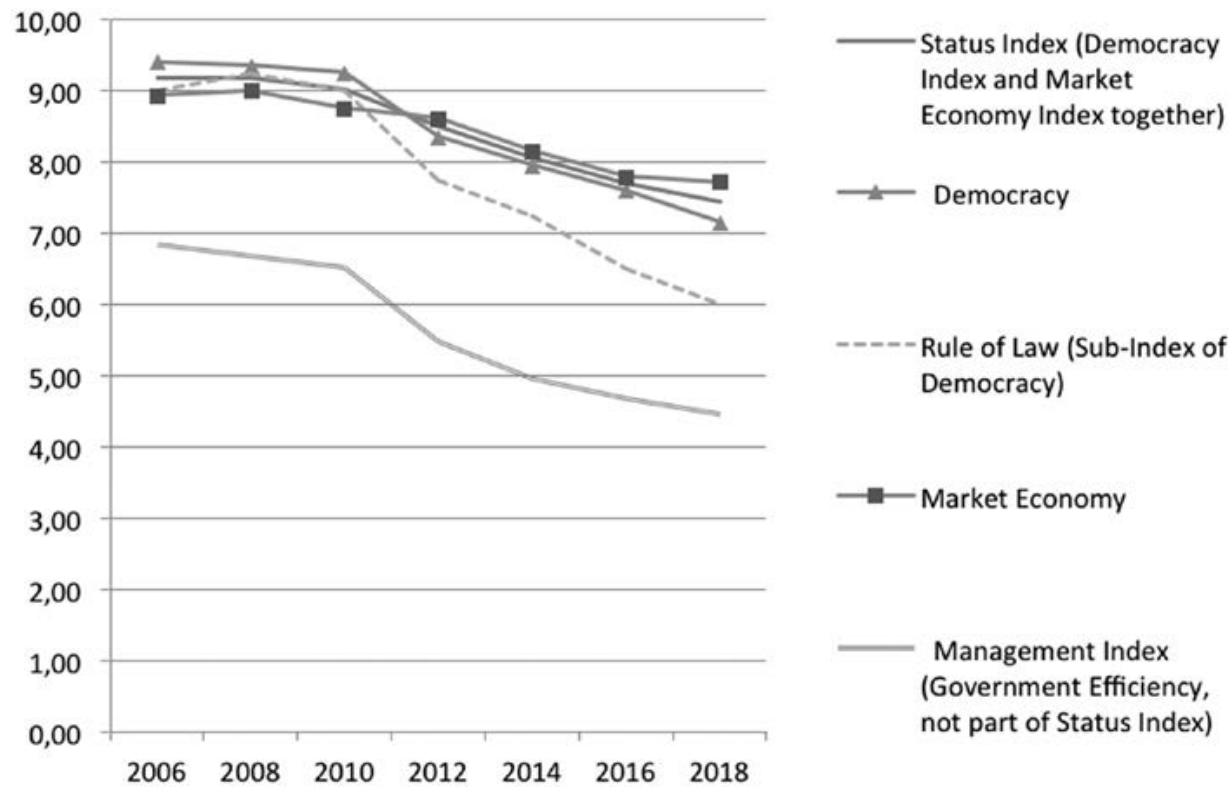

índices del Estado de Derecho, que capturan varios extremos mediante un solo indicador y, lo que es más significativo, confieren la debida atención a las prácticas reales ${ }^{46}$. Estos índices reflejan claramente la erosión del Estado de Derecho que durante los últimos años está teniendo lugar en Hungría y respecto de la cual todo indica que dicho proceso va a continuar en el futuro. A continuación, presentaré brevemente los valores relativos al subíndice referido al Estado de Derecho contenido en el Índice de Transformación Bertelsmann. El Índice de Trasformación Bertelsmann, conocido como (índice de status) es el promedio entre el índice de la economía de mercado y el índice de democracia, que incluye

46 Sobre los detalles metodológicos mencionados y mas información sobre los índices del Estado de Derecho, vid. A. JАКАВ \& V. O. LÖRINCZ, 'International Indices as Models for the Rule of Law Scoreboard of the European Union: Methodological Issues '21 Max Planck Institute for Comparative Public \& International law (2017), www.ssrn.com/abstract=3032501. Los distintos índice del Estado de Derecho se realizan sobre la base de distintas fuentes, entre las que están los datos (como el presupuesto del poder judicial, la oponión de expertos (de juristas constitucionales) y/o las encuestas de opinion pública (por ejemplo, la percepción judicial). Muestro aquí mi agradecimiento en la preparación de los gráficos a V. Olivér Lőrincz and N. Taletovic. El uso de estos índices no convierte la metodología doctrinal de análisis jurídico en algo obsoleto, pero en situaciones en las que existen un gran número de cambios y problemas en donde crece la discrepancia entre las normas y los hechos son especialmente útiles (en todo caso también se incluyen las opiniones de los expertos y las opiniones de la doctrina tradicional). 
el Estado de Derecho según la conceptualización de Bertlsmann. Este mide cuatro elementos del Estado de Derecho, un total de diecisiete parámetros a través de cuarenta y nueve criterios que se superponen parcialmente: (1) en primer lugar, la separación de poderes; (2) en segundo lugar, la independencia judicial, (3) en tercer lugar, la persecución del abuso de poder y, (4) en cuarto lugar, los derechos fundamentales. Las cifras muestran una erosión gradual del Estado de Derecho en Hungría. Por su parte, el índice de gestión es un indicador distinto que mide la eficiencia del gobierno. Este también muestra una tendencia a la baja, es decir que la erosión del Estado de Derecho no impulsó la eficiencia.

\section{Una narrativa deshonesta: ¿o por qué Hungría necesita una nueva Constitución?}

En el momento en el que se redactó la Ley Fundamental se dieron diversas razones oficiales de por qué Hungría necesitaba una nueva Constitución ${ }^{47}$. Finalmente prevalecieron dos argumentos principales. (a) El primero señalaba que la Constitución comunista de 1949 debía ser remplazada; (b) el segundo, por su parte, argüía que una nueva Constitución marcaría el fin de dos décadas de «confusión» después del fin del socialismo en 1989/1990.

El primer argumento (a), relativo al cierre de la confusión subsiguiente a al periodo socialista carece de todo fundamento tanto formal como material: la Constitución de 1949 fue sustituida en 1989/1990 y, aparte de unas pocas frases insignificantes que podrían haberse eliminado mediante una simple enmienda constitucional, no quedaban en 2010/2011 restos socialistas en el texto. En este sentido el principal argumento formal fue que en el título de la Constitución aún se contenía una referencia al año 1949 (se titulaba Ley n. ${ }^{\circ}$ XX de 1949).

El segundo argumento (b), referido al fin simbólico de las dos décadas anteriores (las que transcurren desde 1989/90 hasta 2010), fue, sin embargo, un argumento que los partidos del gobierno pudieron haber tomado, al menos parcialmente en serio $^{48}$. Estas dos décadas (y en particular la segunda), fueron de hecho poco exitosas para el país: los Estados centroeuropeos vecinos alcanzaron a Hungría, que hasta entonces había sido el líder regional e, incluso, algunos la superaron en términos de ciertos indicadores económicos. A pesar de que los políticos debían haberse mirado entonces al espejo, fue más sencillo culpar a la Constitución o al adversario político de esa situación. De este modo la sociedad húngara quedó atascada y cada vez más enredada en una versión nacional de la guerra fría en la que la victoria sobre la oposición justificaba cualquier medio: la corrupción, el endeuda-

47 Narratives are 'not just of how we do things around here, but also why we do things the way we do.' Vid LOWNDES \& ROBERTS, supra nota 4, p. 64.

48 Para su simbolismo vid. L. Sólyom, Das Gewand des Grundgesetzes: Zwei Verfassungsikonen — Ungarn und Deutschland (2017). 
miento público, la baja calidad del gobierno o, incluso, su nula calidad. Se trató de un periodo problemático e infructuoso que se cerró con la nueva Constitución. Sin embargo, los problemas persistieron después de 2010/2011 e, incluso, algunos de ellos se agrandaron: la corrupción ha aumentado, se ha centralizado y está más organizada; la deuda del Estado no se ha reducido sustancialmente (aunque Hungría ha nacionalizado los fondos privados de pensiones y ha conseguido crecimiento mediante la supresión de los impuestos especiales); y la calidad de la gobernanza tampoco ha mejorado, es más, en ciertas áreas, por ejemplo en el campo de la educación pública se ha producido un deterioro espectacularmente dramático ${ }^{49}$. Por todo ello, la Ley Fundamental fue incapaz de convertirse en la simbólica línea divisoria que los partidos gobernantes pretendían; de hecho en su lugar ha pasado a simbolizar la erosión del Estado de Derecho y, como suele pasar en estos casos, se ha convenido en la imagen de todo este régimen (con su corrupción sistemática y sus tendencias autoritarias). En realidad, la Ley Fundamental perpetúa una visión fracasada y claramente deshonesta en ciertas materias respecto de ciertos problemas morales e intelectuales especialmente arraigados, por ejemplo, existe una clara continuidad en la negativa a divulgar los archivos secretos tras el fin del régimen socialista (Hungría continúa tratando la información del servicio secreto comunista de forma opaca) y, además, los problemas de corrupción en la contratación pública se han generalizado desde 1990.

Cuando se busca un arquetipo que describa mejor la narrativa del sistema jurídico actual, el que resulta más apropiado es el propio de la era socialista. Esta circunstancia es de lo más sorprendente, ya que la razón más importante para la adopción de la nueva Ley Fundamental fue superar la Constitución socialista (o incluso la «comunista») anterior (1949/1989). En el plano político, el actual gobierno húngaro emplea sistemáticamente una retórica política anticomunista, pero sus ideas implícitas y a veces también las explícitas sobre la ley evidencian, de hecho, significativas reminiscencias de la doctrina legal socialista. No es una mera coincidencia fortuita, sino que, más allá de esto, se trata una clara e identificable continuidad de la teoría jurídica marxista, que ha sobrevivido al cambio político y que persiste en el pensamiento jurídico de Hungría ${ }^{50}$. Esta llegó a convertirse en dominante de forma evidente después de 2010, habiendo sido elevada en parte al nivel de la narrativa oficial ${ }^{51}$. Esta continuidad no es solo un mero remanente del pasado sino que ha conllevado también el refuerzo de varias de sus características, circunstancia esta inducida en parte por la similitud entre ambos funcionamientos políticos, en particular por el estatismo y el voluntarismo y, en parte, por los elementos de la teorías socialista que perviven como residuos mentales ${ }^{52}$.

49 I. PolónYi, 'Oktatáspolitikai kísérletek és kudarcok' in Hegymenet, supra nota 17, pp. 379-400.

50 Para más detalles vid., A. JAKAB and M. Hollán, 'Socialism's Legacy in Contemporary Law and Legal Scholarship: The Case of Hungary' 2-3 Colum. J. E. Eur. L. 95 (2004).

51 Vid. Tölgyessy, supra nota 33.

52 La expresión «residuos mentales» se ha tomado prestada de Offe, supra nota 18, p. 210. 
La doctrina jurídica oficial marxista-leninista (y particularmente la doctrina constitucional) puede resumirse brevemente en unos pocos preceptos (vid. infra $)^{53}$. En todo caso, no afirmo que estos formen en abstracto el conjunto de la esencia de la teoría jurídica o constitucional marxista, en tanto que un jurista erudito en esta doctrina legal probablemente reconstruya sus tesis de una forma diferente; no obstante, los preceptos que a continuación se enumeran se muestran como los más relevantes para entender el legado contemporáneo de esta ideología en Hungría. Evidentemente el enfoque gubernamental respecto de la ley evita los fundamentos teóricos de este pensamiento jurídico y en tanto en cuanto surge accidentalmente alguno de sus fragmentos, es difícil vincularlos entre sí conjuntamente en una doctrina jurídica abstracta y coherente ${ }^{54}$. Ahora bien, algunos de los elementos de la doctrina jurídica marxista, sobre los que trato a continuación, tienden aún a resurgir. Seguidamente resumiré primero cada uno de esos preceptos para describir después cómo y en qué medida perviven en la actualidad ${ }^{55}$.

(1) La ley es solo un impedimento de naturaleza técnica, y no es una barrera real para la política; la ley refleja la voluntad de la clase dominante - el instrumentalismo jurídico, esencialmente niega la idea del constitucionalismo.

Constituye una infame manifestación de ello el uso desenfrenado de la legislación, incluida la elaboración de una constitución, para, por un lado, ponerla al servicio de los fines concretos de las políticas del poder (ejemplos concretos son en este sentido las leyes sobre medios de comunicación, sobre el procedimiento electoral y la publicidad política en espacios públicos) y; por otro lado, otorgar beneficios económicos a un determinado grupo de interés concreto (como sucede, por ejemplo, con la legislación del juego, la venta al por menor de tabaco o diferentes leyes tributarias). Otro claro ejemplo de legislación instrumentalizada ${ }^{56}$ es la lex CEU que es descaradamente inconstitucional (y probablemente también contraviene el Derecho de la UE), que posiblemente buscaba desviar el debate político de otros asuntos más incómodos como la corrupción, la situación de los servicios públicos de salud y el sistema educativo. El concepto instrumentalista de la Ley solo se ha transformado en el sentido de que «la clase trabajadora» ha sido sustituida por «la nación», en cuyo interés se legitiman violaciones formales

53 En referencia al uso de la teoría legal marxista en este trabajo, me refiero al socialismo normativo de origen soviético: por decirlo de otro modo, a la teoría jurídica marxista leninista. Para más detalles vid. por ejemplo., J. N. Hazard, Communists and their law (1969); W. E. Butler, Soviet Law (1988).

54 Sobre el «estado illiberal», vid. infra.

55 Sobre la continuación de la influencia comunista, con más referencias, vid. JAKAB, supra nota 50.

56 Vid. S. WALKen, Liberal Hungarian university warns Victor Orbán could force it abroad, The Guardian (May 15. 2018), www.theguardian.com/world/2018/may/15/central-european-university-ready-to-move-out-of-hungary; L. Sólyom, M. Lévay, Z. Szente \& A. Jakab, Amicus Curiae a Lex Ceu ügyében (Amicus Curiae in the case of Lex CEU), (June 12 2017) www.public.mkab.hu/dev/dontesek.nsf/0/af27b40ba3b0b821c1258109003f9b19/\$FILE/II_1036_5_2017_\%C3\%A111\%C3\%A1sfoglal\%C3\%A1s.002.pdf/ II_1036_5_2017_\%C3\%A111\%C3\%A1sfoglal\%C3\%A1s.pdf 
del Ordenamiento y en cuyo interés, también, se aprueban leyes que contravienen los principios del constitucionalismo occidental.

(2) De entre los distintos métodos de interpretación existentes se adoptan preferentemente aquellos enfoques de naturaleza textual, en tanto que las soluciones de tipo creativo, como la referencia a los fines generales texto normativo, conferiría a los jueces una margen de interpretación excesivo, que podría pasar por antidemocrático, dando lugar a una quiebra de la certeza jurídica. En realidad en la redacción original se daba un paso adelante en el fomento de la interpretación teleológica, algo habitual dentro de la cultura jurídica occidental y también en la húngara antes de la Segunda Guerra Mundial ${ }^{57}$. Sin embargo, las enmiendas Cuarta y Séptima de la Ley fundamental tenían por objeto frenar la capacidad tanto del Tribunal Constitucional como de los Tribunales ordinarios de poder reinterpretar (reescribir) las reglas jurídicas formales ${ }^{58}$.

(3) Descartar el principio de separación de poderes, en favor de la concentración del poder, 0 «centralismo democrático». En el texto de la Ley Fundamental se contiene expresamente, aunque en cierta medida de forma farisea, el principio de separación de poderes que formalmente es parte de la Constitución. Sin embargo, en el marco de las prácticas reales presenciamos una evidente erosión de este principio de división del poder. Resulta complejo evidenciar estas prácticas con los métodos legales tradicionales ya que en la práctica se producen bien mediante el reclutamiento de cargo o bien a través de mecanismos informales de presión. Durante la época socialista, los tribunales constitucionales se describían como instituciones elitistas y antidemocráticas, que carecían de legitimación original y, por tanto, sin capacidad para intervenir en los procesos políticos, donde los jueces eran, además, meros burócratas. Esta visión se mantiene hoy en Hungría, incluso tras el fin del socialismo, en el marco del discurso público, en donde además se expresa una postura abiertamente hostil y sin precedentes por parte de los niveles políticos más importantes, por ejemplo, cuando se califica a la jurisprudencia constitucional como «arúspice» ${ }^{59}$.

(4) La eficacia del Derecho internacional proviene de la soberanía estatal de la cual se deriva.

Esto es algo que se experimenta de manera cotidiana, comenzando por las declaraciones en las que se retrata a la Comisión Venecia como parte de una

57 A. Jакав, 'A birói jogértelmezés az Alaptörvény tükrében' 2 Jogesetek Magyarázata 86 (2011).

58 Sobre el formalismo judicial de las, aunque cada vez menos, persistentes tradiciones socialistas, vid. M. MatZaK, M. BenCZE Z. KüHN, 'EU Law and Central European Judges: Administrative Judiciaries in the Czech Republic, Hungary and Poland Ten Years after Accession' in Central European Judges under European Influence (Michael Bobek ed., 2015).

59 Los cambios en las normas jurídicas relativas al Tribunal Constitucional desde 2010 pueden explicarse fundamentalmente por el objetivo de los constituyentes de separar al Tribunal de la legislación políticamente relevante. Vid. F. GÁrdos-Orosz, 'Alkotmánybíróság 2010-2015' in A magyar jogrendszer állapota, supra nota 10, p. 442. 
conspiración internacional liderara por el financiero judío de origen húngaro George Soros, pasando las campañas de cartelería estatal en las que se incita al odio contra los migrantes, contra Naciones Unidas y contra la Unión Europea, a la que únicamente se refieren como Bruselas. Además, en los últimos años también hemos visto una resolución parlamentaria en la que se criticaba duramente a una sentencia de Estrasburgo, a pesar de que posteriormente la sanción impuesta por dicho pronunciamiento fue efectivamente satisfecha al demandante ${ }^{60}$. En paralelo, esta posición respecto al Derecho internacional aparece también en ciertas decisiones del Tribunal Constitucional que prescinde totalmente de las disposiciones sobre esta materia contenidas en la Ley Fundamental ${ }^{61}$.

Las similitudes con el antiguo régimen son evidentes y, aunque uno o dos elementos puedan tener otras fuentes, como por ejemplo el positivismo jurídico clásico o los conceptos autoritarios de la Ley ${ }^{62}$, sin embargo, sus orígenes provienen directamente del socialismo e, incluso, si observamos más de cerca cómo esta postura se manifiesta se nos revela a menudo su fuente marxista.

La resistencia frente la revisión judicial de los actos parlamentarios, por ejemplo, es también característica del constitucionalismo británico clásico (si bien esta no pervive en la actualidad en su naturaleza original desde que en 1988 se aprobara la Human Rights Act y desde que se introdujo una jurisprudencia moderada en materia de derechos fundamentales). Se trivializa con el ejemplo británico ante la audiencia húngara, pues existen grandes diferencias entre el sistema húngaro y el sistema británico, que, al carecer de una constitución escrita permite la adopción de cualquier ley por una simple mayoría. Así todo intento por transponer el concepto británico de "political constitucionalism» fallaría, al tratarse el caso húngaro de contexto en el que existe un medio institucional diferente ${ }^{63}$. Además, el rechazo a la creatividad por parte de los jueces no solo era algo característico de la teoría legal marxista, sino que también de una significativa rama de la doctrina jurídica estadounidense, la orginalista, que mantiene una visión similar ${ }^{64}$. Sin embargo, mientras los originalistas tratan de descubrir el sentido original de ciertos términos jurídicos específicos, esto no se produce al usarse esta metodología en la práctica real

60 Parl Dec 58/2012. (VII. 10.) OGY hat.

61 El art. Q de la Ley Fundamental contiene la obligación de conformidad con la ley internacional. Sobre los intentos de neutralizar esta disposión, vid. AB [Constitutional Court] Dec.34/2013., XI. 22.(Hung.), sep op by Justice Béla Pokol [83]-[85]; AB [Constitutional Court] Dec 7/2014. III. 7. (Hung.), sep op by Justice Béla Pokol [113].

62 B. Pokol, 'Separation of Power and Parliamentarism in Hungary' 37 E. Eur. Q. 67 (2003); B. POKOL, The Juristocratic State: Its Victory and the Possibilities of Taming (2017).

63 Sobre constitucionalismo político vid. R. Bellamy, Political Constitutionalism (2007). Para una revisión crítica de la recepción del concepto en Hungría. Vid. A. Antal, 'Politikai és jogi alkotmányosság Magyarországon' 22 Politikatudományi Szemle 48 (2013), con más referencias.; I. STUmpF, E. Allam — alkotmányos korlátok (2014).

64 Vid., por ejemplo, A. SCALIA \& B. A. Garner, Reading Law: The Interpretation of Legal Texts (2012). 
húngara. Un significativo número de promotores del actual gobierno, entre los que se encuentran expertos en Derecho, comenzaron sus carreras como teóricos jurídicos marxistas, y algunos de ellos continúan trabajando (entre otras cosas) con terminología marxista ${ }^{65}$.

\section{El efecto combinado de los distintos componentes}

En 2011 Lászo Sólyom (el primer presidente del Tribunal Constitucional Húngaro entre 1990 y 1998, y también Presidente de la República entre 2005 y 2010) escribió que creía en la supervivencia de las Instituciones del constitucionalismo a través de la cultura constitucional y de la jurisprudencia del Tribunal Constitucional, a pesar de las prácticas gubernamentales y, también, de ciertas disposiciones cuestionables en la nueva Ley Fundamental ${ }^{66}$. Sin embargo, desafortunadamente, su visión optimista no ha llegado a convertirse en realidad. Si bien la cultura constitucional logró efectivamente atenuar algunas enmiendas groseras a leyes formales, la reforma constitucional de 2013 dejó meridanamente claro que todo lo con ello puede hacerse es simplemente retrasar el deterioro, pero no impedirlo. Desde entonces, no solo generan preocupación las prácticas gubernamentales y legislativas sino también las del propio Tribunal Constitucional (particularmente las tácticas dilatorias empleadas en ciertos casos políticamente delicados). Las instituciones existentes se han debilitado considerablemente — según los índices sobre el Estado de Derecho descritos anteriormente- $-\mathrm{y}$ no se ha establecido ninguna nueva institución sólida que haya ocupado su puesto. Una de las principales funciones de toda institución es incrementar la predictibilidad, reforzar el cumplimiento de la ley y, por lo tanto, promover el pensamiento a largo plazo. Esto, sin embargo, contrasta con las políticas pragmáticas del poder «ad hoc», ejercidas por el actual régimen, guiadas por el corto plazo y que niegan casi completamente las consideraciones reales de la política pública. Así en diversas ocasiones el Gobierno ha violado normas formales del Ordenamiento Jurídico que debiera ejecutar. Es por ello que la práctica política real, completamente centrada en controlar el momento político se resiste a cualquier narrativa sustantiva (o, en este caso, a una fundamentación teórica) ${ }^{67}$.

65 Csaba Varga, 'A joguralom és színeváltozásai idealizáció és ideokratikus nyomásgyakorlás között' Pázmány Law Working Papers No. 12 (2016), www.plwp.eu/evfolyamok/2016/170-2016-12 (one of the most wellknown Marxist legal theorists before 1990); Béla Pokol, Globális uralmi rend (2008) (working with the neo-Marxist theses of Michael Hardt és Antonio Negri).

66 L. Sólyom, 'Elöszó: Az alkotmányos kultúra szerepe' in, Az Alaptörvény keletkezése és gyakorlati következményei 11-14 (András Jakab 2011).

67 Los fundamentos teóricos son, por su naturaleza, fútiles en este régimen. Sobre los diversos intentos, vid. Zs. A. VARGA, Eszményből bálvány? A joguralom dogmatikája (2015); A.RIXER (ed.), Állam és közösség: Válogatott közjogi tanulmányok Magyarország Alaptörvénye tiszteletére (2012). 


\section{QUÉ HACER: MANUAL DEL FORTALECIMIENTO INSTITUCIONAL EN EL CONTEXTO DE LA HUNGRÍA COMTEMPORÁNEA}

La mayor dificultad del fortalecimiento institucional descansa sobre el hecho de que los elementos informales no son directamente accesibles, por ejemplo, para ellos no hay procedimiento de reforma, es más, posiblemente los mismos saboteen las reformas formales. Algunos de los desafíos del fortalecimiento institucional en Hungría tienen su origen en el legado socialista, mientras que otros están determinados por rasgos provenientes de momentos anteriores a dicha era socialista.

Mientras que los elementos informales pueden eventualmente cambiarse con la ayuda de las instituciones — una estrategia que recuerda mucho al notorio intento del barón von Munchhausen- ${ }^{68}$, el éxito del fortalecimiento institucional depende realmente de las prácticas y la narraciones apropiadas, quienes a su vez dependen las instituciones correctas ${ }^{69}$. La solución está un una combinación entre del deseo de restaurar y la aceptación de ayuda exterior. Es crucial para Hungría abandonar el espejismo de la soberanía y adaptarse a la civilización occidental asumiendo los compromisos que se concluyen en los momentos más solemnes de la historia de una nación, y mediante ello proporcionar una garantía de que incluso en tiempos menos solemnes su élite política no se desviará de dicho camino dando rienda suelta a sus más paganos instintos. Desafortunadamente, un escenario como este donde las élites políticas alcanzan un compromiso difícilmente tiene éxito, y generalmente es seguido por una época de gran agitación. De hecho, esto también conlleva el riego de poner al país en un camino equivocado en lugar de devolver la sobriedad a las élites: un ejemplo de ello para Hungría lo constituye el Tratado de paz del Trianon (por el que Hungría perdió dos tercios de su territorio después de la Primera Guerra Mundial y tras el cual se culpó al liberalismo de la miseria de la nación) o los conflictos que se prorrogan durante siglos e, incluso, la degradación de muchos Estados latinoamericanos (donde las crisis dan lugar a nuevas crisis en vez de a recuperar la sobriedad) ${ }^{70}$.

1. Por desgracia no existe ninguna receta mágica para el fortalecimiento institucional; no obstante, nosotros proponemos formular una serie de

68 Para unas consideraciones similares, aunque con una terminología más optimista, vid. A. AlessinA \& P. GiUliano, 'Culture and Institutions' 53 J. Econ. Literature 898, 928 \& 938 (2015), on two-way effects, interdependence, and mutual feedback effects.

69 'Thus good citizens make good institutions, and good institutions are 'good' to the extent that they generate and cultivate good citizens or the 'better selves' of citizens...' Offe, supra nota 19, p. 200.

70 El consenso de la élite pueda desarrollarse de una forma evolutiva (por ejemplo, las política belga e italiana despúes de la II Guerra Mundial) o mediante unos acuerdos expresos de naturaleza simbólica (por ejemplo, la Bill of Rights de 1689 o los Pactos de la Moncloa de 1978. Para consultar un gran número de ejemplos, vid. Higley \& Burton, supra nota 21, pp. 55-106 \& 139-180. 
conclusiones al respecto que vale la pena tener en cuenta. En materia de reglas formales deberíamos aprender las lecciones de nuestro pasado más reciente y reformar la normativa constitucional y legislativa que regula las instituciones constitucionales más importantes ${ }^{71}$. En lugar de una recodificación integral el camino a seguir debe ser el de una serie de pequeños pasos $^{72}$. Las grandes recodificaciones pueden tener consecuencias imprevisibles, precisamente porque las instituciones no son la suma de sus normas y porque, al mismo tiempo, este tipo de recodificación exacerba la incertidumbre, aumentando así la desconfianza en esas instituciones ${ }^{73}$. Por lo tanto, el éxito de las reformas institucionales depende en mucha mayor medida de la confianza y de la práctica real de los interesados, que de la calidad de cada uno de las reglas concretas (que son importantes en otro sentido) ${ }^{74}$.

No puedo dar aquí cuenta de cada uno de esos pequeños pasos a llevar a cabo, pero sí señalaré algunos de sus principales elementos abstractos que, en su caso, requieren de soportes legislativos e, incluso, constitucionales: autonomía institucional, transparencia, gobierno basado en normas, estabilidad, meritocracia, predictibilidad, legislación no motorizada, normas más rigurosas para la preparación de las leyes, garantías de financiación constitucionales y fondos para universidades y otras instituciones educativas (con prohibición de ayudas individuales ad hoc), garantías constitucionales de la democracia interna en los partidos políticos, y transformar la financiación de las confesiones religiosas, de las fundaciones y las organización propias de la sociedad civil en una decisión que no dependa del gobierno. Entre otras medidas el reforzamiento en estas áreas, llevado a cabo mediante la adopción de las oportunas reglas formales, puede romper con las actuales prácticas. Las oportunidades que ofrecen los medios de una integración europea más estrecha también pueden jugar un papel fundamental en la construcción de garantías formales como, por ejemplo, la integración en el sistema de la fiscalía europea, que es más riguroso (cf. Ulises y las sirenas).

También debemos tener en cuenta que trasplantar de modo idéntico las soluciones regulatorias occidentales a otros países puede resultar un fracaso espectacular ${ }^{75}$. Esto no quiere decir que «Hungría no esté cortada por el patrón para el Estado de Derecho». Se trata de todo lo contrario: los elementos culturales, que son presupuestos para los estados occidentales basa-

71 Para más ejemplos y sugerencias en este sentido vid. JAKAB \& GAJDUSCHEK, supra nota 2.

72 Para unas conclusiones similares vid. A. SAjó, 'Az állam müködési zavarainak társadalmi újratermelése' 55 Közgazdasági Szemle 690, 710 (2008).

73 Sobre los peligros del activismo diseñado, vid. D. STARK, 'Path dependence and privatization strategies in East Central Europe' 6 E. Eur. Pol. \& Societies 17 (1992).

74 OFFE, supra nota 20, p. 215.

75 S. Holmes, 'Can Foreign Aid Promote the Rule of Law?' 8 E. Eur. Const. Rev. 68 (1999). 
dos en el Estado de Derecho, deben poco a poco establecerse de forma consciente, incluso si es necesario mediante la adopción de reglas formales que puedan o no existir en los modelos de Estado occidental. En otras palabras, donde falten elementos culturales necesarios las normas formales deben desviarse de aquellas que de otro modo se adoptarían, para respaldar uno u otro elemento cultural óptimo ${ }^{76}$, debiendo en ese caso optarse por «la segunda mejor» norma. Esto es válido para el conjunto de la población donde la dependencia del poder público, particularmente del Estado, debe reducirse significativamente (por ejemplo, asegurando garantías personales y financieras concretas que promuevan la independencia respecto de los partidos políticos en los hospitales, las escuelas, las universidades y otros establecimientos sociales y culturales). Además, esto también puede aplicarse a las élites, donde aquellas actitudes que fomenten el compromiso deben ser fortalecidas (por ejemplo, mediante un sistema electoral que permita a los ciudadanos prescindir de ciertos políticos controvertidos en vez tener que optar por cambiar su voto a otro partido ${ }^{77}$.

2. En el nivel de la práctica real, se discute frecuentemente sobre el imperativo de remover y cambiar a los altos cargos de ciertos órganos constitucionales (como el Tribunal de cuenteas, el Tribunal Constitucional, la jefatura de la Fiscalía...). Deshacerse de los «soldados del partido» más visibles del actual régimen autoritario (que también en la práctica se han venido comportando efectivamente como soldados del partido), seguramente incrementaría la credibilidad del Ordenamiento Jurídico; aunque esta medida por sí sola no resolvería los problemas existentes (de hecho, podría, incluso, exacerbarlos, dependiendo de lo aguda que sea la división entre «nosotros» y «ellos»). Lo que sí que es realmente importante es el estricto cumplimiento de las normas formales y su correspondiente fortalecimiento. Pues, en cualquier caso, las mejores garantías formales pueden fracasar allí donde los servidores públicos busquen deliberadamente incumplirlas o no hacer dada ante su quiebra. La estabilidad de las normas formales (a excepción hecha de los momentos de cambio de régimen) es también un elemento importante, de hecho, en algunos casos es aún más importante que el contenido de las propias normas ${ }^{78}$.

76 Para un tratamiento similar sobre los elementos formales e informales de la Constitución vid. A. Vermeule, 'System Effects and the Constitution' 123 Harv. L. Rev. 4 (2009).

77 Sobre los efectos ventajosos de los votos negativos y los votos plurales en los sistemas electorales, en una forma comprensible, vid. D21, http://www.d21.me, or in a more academic style with detail, vid. D. CAHAn \& A. Slinko, 'Electoral Competition under Best-Worst Voting Rules' (Aug. 10 2016), https://ssrn.com/ abstract =2850683; Martin Gregor, 'The Optimal Ballot Structure for Double-Member Districts' CERGE-EI Working Paper Series 493 (Sept. 25 2013), www.ssrn.com/abstract=2347118.

78 La inversión extranjera directa en el centro y este de Europa se vincula más la estabilidad de las normas fiscales que a su contenido real, vid. Kelly Edmiston, Shannon Mudd \& Neven Valev, 'Tax Structures and FDI: The Deterrent Effects of Complexity and Uncertainty' 24 Inst. for Fiscal Stud. 341 (2003). 
3. Finalmente, quizás el más importante prerrequisito es encontrar una narrativa honesta y creíble para el sistema judicial que sea aceptable para toda la sociedad en su conjunto. La forma en la que se percibe y se habla del sistema jurídico por parte de la sociedad húngara es muy contradictoria, y ello no es solo el producto de unos pocos años del pasado. En palabras de Györdy Gajduscek: a pesar de que los ciudadanos no confíen en el Estado o en la Ley, sin embargo, recurrirán a ambos para solucionar sus problemas. Demandarán una normativa extremadamente detallada y con duras sanciones para cualquiera que incumpla las leyes; pero si se trata de aplicarse la ley a uno mismo entonces burlarán de buena gana las normas y esperarán un tratamiento equitativo. Todo ello va aparejado a una cultura social de excepcional pesimismo, cinismo y anomía. Lo que realmente se echa en falta es un sistema de valores coherente que sea compartido por la mayoría de los ciudadanos, incluso aunque este nazca de los elementos más básicos de la ley (el papel de los derechos y deberes fundamentales, la presunción de inocencia). De hecho, los sujetos a menudo profesan valores que se encuentran en situación disonante unos con otros. Por ejemplo, los integrantes de la sociedad estarán de acuerdo en que la sociedad es injusta, aunque no estén dispuestos a hacer nada para cambiarla. Casi todos los individuos creen en su fuero interno que ellos cumplen más y mejor que cualquier otro con las normas morales y jurídicas ${ }^{79}$.

La estructura de la sociedad se aglutina mediante ciertos valores y prohibiciones que no suelen ser directamente cuestionadas, aunque sí puedan ser moderadamente reinterpretadas: desde una perspectiva antropológica estos son los tabús. En los tiempos de la Edad Media era la Cristiandad quien desempeñaba este papel y los herejes pagaron un alto precio. En Europa occidental desde la II Guerra Mundial y tras la caída del socialismo en todo el continente, este marco de integración se ha construido a partir de los tabús seculares del constitucionalismo. El siglo Xx puede leerse como la historia de la experimentación y la caída de distintos marcos de integración como nacionalismo o el socialismo. Hoy en día, la democracia y la protección de los derechos fundamentales (razones principales por las que se estableció el Consejo de Europa en 1949) parecen ser las únicas narrativas racionales para organizar la sociedad. No ha surgido ninguna otra adecuada a pesar de que dicha narrativa ha sido claramente perturbada y ha experimentado diversas crisis. Sin embargo, ello únicamente ha servido para poner de manifiesto lo extremadamente diversas que son las fuentes de frustración y descontento. En los últimos tiempos el gobierno ha invocado la soberanía como argumento para justificar casos de corrupción y para rechazar sin más examen

79 G. Gajduschek, 'Jogtudat és értékvilág — mint a magyar jogrendszer környezete' in, A magyar jogrendszer állapota, supra nota 10. 
cualquier crítica externa (tanto de la Unión Europea como internacional) que tenga que ver con la violación de los derechos fundamentales. Estas referencias al pueblo y/o a la soberanía son una simple herramienta retórica en manos del gobierno para justificar su propia corrupción y sus violaciones de la ley. Por consiguiente, la noción de soberanía debería ser redefinida por una nueva narrativa o, alternativamente, las referencias a la misma deberían evitarse en la medida de lo posible ${ }^{80}$.

El experimento húngaro del Estado iliberal solo podría sostenerse a largo plazo en tanto que la gran narrativa del proceso de integración europeo se resquebrajara, bien formalmente bien en el nivel de sus prácticas reales. Afortunadamente, a pesar de los desafíos este no parece un escenario muy realista, aunque el futuro éxito o no de la reconstrucción del sistema político húngaro depende en gran medida de si Hungría es capaz de llevar a cabo las tareas de fortalecimiento institucional necesarias. Esto no solo implica elevar la narrativa de la democracia y del Estado de Derecho (incluida la protección de los derechos fundamentales) al nivel de tabú ${ }^{81}$, sino también asegurar los pilares morales del Ordenamiento Jurídico. No podemos esperar que los ciudadanos consideren que se puede confiar en los valores constitucionales seculares y los profesen por sí mismos en tanto en cuanto sus anteriores violaciones quedan sin culpables y sin sanción ${ }^{82}$.

El problema crucial del fortalecimiento institucional en el sistema constitucional del 89/90 (más allá de la corrupción), radicaba en la cuestión de la justicia y trato con el pasado (por, ejemplo con la narrativa) ya que ambos fueron escondidos bajo la alfombra mediante una peculiar interpretación de las normas formales ${ }^{83}$.

80 A. JAKAB, 'Neutralising the Sovereignty Question: Compromise Strategies in Constitutional Argumentations about the Concept of Sovereignty before European Integration and since' 2 Eur. Const. L. Rev. 375 (2006).

$81 C f$. denunciando los valores liberales, especialmente la protección de los derechos fundamentales vid., por ejemplo, V. Orbán, PM of Hung., Speech at the $25^{\text {th }}$ Bálvános Summer Free \& Student Camp, (July 30. 2014), www.kormany.hu/en/the-prime-minister/the-prime-minister-s-speeches/prime-minister-viktororban-s-speech-at-the-25th-balvanyos-summer-free-university-and-student-camp; V. ORBÁN, PM of Hung., Speech at the $14^{\text {th }}$ Kötcse civil picnic (Sept. 17. 2015), www.kormany.hu/en/the-prime-minister/the-prime-minister-s-speeches/viktor-orban-s-speech-at-the-14th-kotcse-civil-picnic.

82 De acuerdo con lo que dicen los estudios empíricos el pago de impuestos es mayor cuando el régimen es moralmente aceptable, vid. L. Feld \& B. Frey, 'Tax Compliance as a Result of a Psychological Tax Contract: The Role of Incentives and Responsive Regulation' 29 L. \& Pol'y 102 (2007); Valerie Braithwaite, Defiance in Taxation and Governance: Resisting and Dismissing Authority in a Democracy (2009). Respecto de la cuestión de que al final del comunismo las élites tuvieran mayor posibilidad de adquirir más riqueza mediante fórmulas que eran consideradas como inmorales por la gran mayoría de la población, (aunque estas no tuvieran prevista una sanción jurídica) se dio como resultado una pérdida de confianza en el Estado de Derecho. Vid. G. Gajduschek, R. Lenni Kellene: Tények és elemzések a közigazgatás ellenőrzési és bírságolási tevékenységéről 220-237 (2008) (Hung.). Vid. también G. GajduscheK, 'Measuring Cross-Sectorial Law Enforcement Capacity of Regulatory Agencies in Hungary' 11 Transylvanian Rev. Admin. Sci. 108, 122 (2015): 'In the end, those following rules may be considered as 'losers', and breaking norms may become a norm itself.'

83 Según G. Halmai, 'Rise and fall of constitutionalism in Hungary' in, Constitutional. Acceleration within European Union and Beyond 220-223 (P. Blokker ed., $1^{\text {st }}$ ed. 2017), las principales razones del fracaso de la democracia liberal en Hungría son: la falta de una cultura de los derechos fundamentales y de la 
Allí donde colisionan claramente las expectativas legales y las morales - como ocurrió en los tiempos del socialismo y también, en cierto modo, durante la transición del socialismo al Estado de Derecho en 1989/90 e, incluso, también tras ella - tanto las normas morales como las legales se debilitan, lo que conlleva a cierto grado de atonía ${ }^{84}$. Para decirlo de un modo más provocador y comprensible: la sociedad húngara está en una crisis moral ${ }^{85}$. En este sentido es especialmente pertinente indicar que la cuestión de los archivos de los servicios secretos de los tiempos del socialismo tiene que ser abordada ${ }^{86}$ y también que los funcionarios corruptos rindan cuentas; de este modo se podrá reconstruir la confianza pública en las instituciones constitucionales y en el Ordenamiento Jurídico subyacente. Debemos además expresar conscientemente en el discurso político las expectativas morales respecto de los integrantes de la sociedad y de las figuras públicamente relevantes $^{87}$, es por ello que debemos posicionarnos en contra de ciertos comentaristas políticos sabelotodo que aparecen en los medios de comunicación ofreciendo una interpretación de las violaciones de las normas por parte de los políticos como si de un éxito se tratara en el marco de la «lógica de la política». No solo son destructivos para las instituciones, sino que además reflejan la falta de conocimiento científico sobre cómo funcionan las instituciones.

Para tener éxito es importante dotar a las nuevas generaciones de juristas con el necesario aparataje teórico ${ }^{88}$. La Ley no es solo una suma de reglas que tienen que aprenderse de memoria. Actualmente, los estudiantes de Derecho que aprueban los exámenes finales tienen un conocimiento preciso del procedimiento administrativo. Sin embargo, cuando se les pregunta por qué un país que se basa en el Estado de Derecho posee un modelo superior o, qué sentido tiene la demo-

tradiciones democráticas liberales, una cultura de victimización en la narrativa nacional, la falta de éxitos económicos, la pérdida de un constitucionalismo cívico o participativo (y con demasiado énfasis en las soluciones judiciales), y un sistema electoral no proporcional.

84 La sociedad húngara no solo se caracteriza por un bajo nivel de confianza, sino también por su anomía: incluso aunque las expectativas normativas sean claras, en el caso de los propios intereses, el pueblo fácilmente desafía estas expectativas (más frecuentemente de lo que es común si lo comparamos internacionalmente). Vid. I. G. Tótн, 'A társadalmi kohézió elemei: bizalom, normakövetés, igazságosság és felelôsségérzet — lennének...' in, Társadalmi riport 2010 (T. Kolosi \& I. G. Tóth eds. 2010).

85 Con la expresión más precisa sociológicamente: «amoral», vid. E. C. BANFIELD, The Moral Basis of a Backward Society (1958), la descripción clásica de la situación en el sur de Italia («familismo amoral»). En el trabajo de Banflied este concepto hace referencia a la imposibilidad de una acción colectiva en favor del interés público, la irrelevancia de cualquier fin más allá de las ventajas materiales para la familia nuclear, la falta de confianza social, el nepotismo, la envidia y la suspicacia. Vid. también la actitud general respecto de la corrupción no solo es más indulgente que la media europea sino también que la media de los Estados vecinos de Hungría. Special Eurobarometer 470. Corruption (2017).

86 Sobre la todavía no resulta naturaleza de esta cuestión, vid., por ejemplo, L. VARGA, Világ besúgói, egyesüljetek! (2006); K. UNGVÁRY, A szembenézés hiánya (2017).

87 Vid. S. Bowles \& H. GinTIS, A Cooperative Species: Human Reciprocity and Its Evolution (2011) sobre el análisis de juego teórico que muestra que el bajo nivel del altruismo y la falta de instituciones que fomenten el altruismo conducen a comunidades más débiles en situaciones conflictivas.

88 SNYDER, supra nota 27 , p. 27 : 'eternal vigilance is the price of liberty'. 
cracia, algunos contestarán con un tópico (quizá formulado en términos legales), si bien la mayoría no serán capaces de dar una respuesta sólida a estas preguntas. ${ }^{89}$ Si estos estudiantes están llamados a ser los operadores jurídicos del futuro difícilmente podrán liderar así el camino para prevenir la erosión de las instituciones. Y ello es así porque no comprenden qué es lo que en el fondo se defiende y se protege más allá del ámbito de las normas formales ${ }^{90}$. Las instituciones aún hoy deben ser continuamente alimentadas y protegidas cada día, de otro modo irán pereciendo paulatinamente ${ }^{91}$. Los juristas deben estar constantemente atentos a ello y no pueden darse simplemente por satisfechos pensando qué «que en su trabajo solo deben interesarse por las reglas formales» ${ }^{92}$.

Las malas noticias son que de entre los tres principales elementos de las instituciones el más sencillo de cambiar es el de las reglas formales, aunque esto precisa también de una acción política como es la legislación. Desafortunadamente, es bastante difícil tener esperanza en que las élites políticas lleven a cabo este tipo de acción en tanto que actualmente se benefician de la situación existente, donde la interacción entre instituciones débiles, incumplimiento de las normas y la desconfianza son mutuamente disruptivas ${ }^{93}$.

Esta aproximación institucionalista de carácter general ofrece dos conclusiones:

1. La experiencia histórica muestra que más allá de una honesta determinación, una reforma institucional radical de todo el sistema jurídico legal solo puede tener éxito si existe presión internacional que, lamentablemente, en este caso ha disminuido desde la entrada de Hungría en la Unión Europea. En otras palabras, el fortalecimiento institucional debe ir de la mano de las obligaciones tanto de la Unión Europea como internacionales, que han sido adoptadas en los momentos políticos más solemnes, a fin de garantizar que la comunidad política no pueda entrar posteriormente en un modo autodestructivo.

89 Z. FLECK et al., Technika vagy érték a jogállam? A jogállami értékek átadása és az előítéletek csökkentése a jogászok és a rendőrtisztek képzésében (2012).

90 Para una visión negativa de los juristas como cumplidores de órdenes y ejecutores de las mismas, vid. SNYDER, supra nota 28, p. 41.

91 LOwNDES \& ROBERTS, supra nota 5, p. 171.

92 Extrañamente, en las normas escritas sobre educación jurídica, nosotros ya tenemos recogido este requisito, vid. Ministerial reg 18/2016. (VIII. 5.) EMMI, pt 7.1.1.c. En la realidad, sin embargo, esto raramente ocurre. Vemos así de nuevo como la elaboración de reglas formales es insuficiente, pero los legisladores, que permanecen en confortable ceguera, consideran que el trabajo ha sido hecho. La norma sobre la superación de la fijación de normas se convirtió en una víctima de la fijación de reglas en sí misma. Qué irónico.

93 Sobre la relación entre la confianza social y las instituciones vid., por ejemplo, B. ROTHSTEIN \& E. M. Uslaner, 'All for All: Equality, Corruption, and Social Trust' 58 World Pol. 41(2005). 
2. Es preciso tener en cuenta y de forma consciente aquellos elementos que están más allá de las reglas formales — como son las prácticas reales y las narrativas - tanto en el ámbito de la legislación, como en de la aplicación del Derecho o en el de la formación jurídica; ello dará como resultado un fortalecimiento paulatino de los elementos culturales sustantivos necesarios para el Estado de Derecho y la democracia. Esto requiere, sin embargo, de una acción política, más concretamente del ajuste de las reglas formales. En tanto que ello no forme parte del interés de los legisladores a quienes esta tarea incumbe, será poco probable superar el punto muerto en que nos encontramos.

TITLE: The failure of constitutional institution-building in Hungary. Informal institutional elements as both preconditions and consequences of effective formal legal rules

ABSTRACT: Institutions are made up of the interplay of three components: (1) formal rules, (2) actual practices and (3) narratives (the two latter ones are referred to jointly as informal institutional elements). However, lawyers in post-socialist countries do not see law through institutionalist lenses, but often nurture a false and simplistic idea of the law: they consider it to be the sum of rules, often disregarding the actual practices of the rules' addressees and narratives attached to the law (encompassing everything from the raison d'etre and goal of the institution, its symbolism, the public discourse surrounding it, and social attitudes towards the institution). This restricted view makes Hungarian lawyers blind and to a certain extent also defenceless. against recent authoritarian tendencies. Institution-building has been a moderately successful feat in Hungary. To put it more pessimistically, it has partially failed since the end of socialism, in particular when it comes to actual practices and narratives. In the Hungarian context, consideration of the problems of institution-building suggests two general conclusions: on the one hand, the lack of unison among the individual elements (rules, practices, narratives) renders institutions less stable and consequently less capable of inducing compliance with the law; on the other, the institutions that have been established have failed to deliver prosperity to the political community. This paper describes the constitution-making of 2010/11 from the perspective of institution-building. This institutionalist view of the law yields two main specific findings: (1) Historical experience shows that besides honest determination, the radical institutional overbaul of a complete legal system can only be successful in the presence of external pressure, the effect of which has unfortunately decreased with Hungary's accession to the EU. That is, institution-building should go hand-in-hand with effective international and EU obligations undertaken in more sober political moments to guarantee that the political community will not later enter into a self-destructive mode. (2) Taking elements beyond mere rules more consciously into account, such as actual practices and narratives in the realm of legislation, the application of the law and legal training would ideally result in the gradual reinforcement of substantive cultural elements. This, however, requires political action, more precisely the adjustment of formal rules. Since this is not in the interest of the incumbent decision-makers, overcoming the impasse seems unlikely for the time being.

RESUMEN: Las instituciones se elaboran como la interacción, de los siguientes tres componentes: reglas formales, practicas reales y narrativas (los dos últimos, las prácticas y las narrativas, se configuran conjuntamente como los «elementos informales»). Sin embargo, los juristas en los estados postsocialistas no ven la ley a través de la lente institucional, y a menudo alimentan una idea falsa y simplista de la ley: en tanto que la consideran como la suma de reglas, normalmente disociadas de su práctica real, de las normas y de las narrativas adjuntas (acompasando todo desde la razón de ser y la finalidad de la institución, su simbolismo, el discurso público que las rodea y las actitudes sociales respecto de la institución). Esta visión restrictiva hace a los juristas hungaros ciegos y en ciertas situaciones los deja indefensos ante las actuales tendencias totalitarias. El 
fortalecimiento institucional ha alcanzado un logro moderado en Hungría. Por decirlo de forma más pesimista, ha fallado parcialmente desde el fin del socialismo, particularmente en relación con las actuales prácticas y narrativas. En el contexto húngaro, las consideraciones sobre los problemas del fortalecimiento institucional sugieren dos conclusiones generales: de una parte, la falta de coherencia entre los elementos individuales (normas, prácticas y narrativas) conduce a unas instituciones menos estables y consecuentemente menos capaces de inducir a la observancia del Derecho; de otra parte, las instituciones que se ban establecido han fallado en la tarea de brindar prosperidad a la comunidad política. Este trabajo describe la elaboración de la Constitución del 2010/2011 desde la perspectiva del fortalecimiento institucional. Esta aproximación institucionalista de carácter general ofrece dos conclusiones: (1) La experiencia histórica muestra que, más allá de una honesta determinación, una reforma institucional radical de todo el sistema jurídico legal solo puede tener éxito si existe presión internacional que, lamentablemente en este caso, ha disminuido desde la entrada Hungría en la Unión Europea. Esto es, el fortalecimiento institucional debe ir de la mano de las obligaciones tanto de la Unión Europea como internacionales, que han sido adoptadas en los momentos políticos más solemnes, a fin de garantizar que la comunidad politica no pueda entrar posteriormente en un modo autodestructivo. (2) Es preciso tener en cuenta y de forma consciente aquellos elementos que están más allá de las reglas formales - como son las prácticas reales y las narrativas - tanto en el ámbito de la legislación, como en de la aplicación del Derecho o en el de la formación jurídica, ello dará como resultado un fortalecimiento paulatino de los elementos culturales sustantivos necesarios para el Estado de Derecho y la democracia. Esto requiere, sin embargo, de una acción política, más concretamente del ajuste de las reglas formales. En tanto que esto no forme parte del interés de los legisladores a quienes esta tarea incumbe, será poco probable superar el punto muerto en que nos encontramos.

KEY WORDS: Hungary, Rule of Law, institution-building.

Palabras Clave: Hungría, Estado de Derecho, fortalecimiento institucional.

FECHA RECEPCIÓN: 30.11.2018 FECHA ACEPTACIÓN: 05.02.2019 
